UNIVERSIDADE DE SÃO PAULO

ESCOLA POLITÉCNICA

MARCO AURÉLIO CESTARI GENICOLO

ESTUDO DE VIABILIDADE PARA IMPLEMENTAÇÃO DE UNIÕES SOLDADAS PELO MÉTODO FRICTION STIR WELDING EM ESTRUTURAS AERONÁUTICAS

São Paulo 
MARCO AURÉLIO CESTARI GENICOLO

ESTUDO DE VIABILIDADE PARA IMPLEMENTAÇÃO DE UNIÕES SOLDADAS PELO MÉTODO FRICTION STIR WELDING EM ESTRUTURAS AERONÁUTICAS

Dissertação apresentada à Escola

Politécnica da Universidade de São Paulo para a obtenção de título de mestre em Engenharia.

São Paulo 
MARCO AURÉLIO CESTARI GENICOLO

\section{ESTUDO DE VIABILIDADE PARA IMPLEMENTAÇÃO DE UNIÕES SOLDADAS PELO MÉTODO FRICTION STIR WELDING EM ESTRUTURAS AERONÁUTICAS}

Dissertação apresentada à Escola

Politécnica da Universidade de São Paulo para a obtenção de título de mestre em Engenharia.

Área de Concentração:

Engenharia Mecânica.

Orientador: Prof. Dr. Marcelo Augusto Leal Alves

São Paulo 
Este exemplar foi revisado e alterado em relação à versão original, sob responsabilidade única do autor e com a anuểncia de seu orientador.

São Paulo, de agosto de 2007.

Assinatura do autor

Assinatura do orientador

\section{FICHA CATALOGRÁFICA}

Genicolo, Marco Aurélio Cestari

Estudo de viabilidade para implementação de uniões soldadas pelo método friction stir welding em estruturas aeronáuticas / M.A.C. Genicolo. -- ed.rev. -- São Paulo, 2007. $62 \mathrm{p}$.

Dissertação (Mestrado) - Escola Politécnica da Universidade de São Paulo. Departamento de Engenharia Mecânica.

1.Juntas soldadas (Viabilidade) 2.Aeronaves I.Universidade de São Paulo. Escola Politécnica. Departamento de Engenharia Mecânica II.t. 


\section{DEDICATÓRIA}

Dedico este trabalho à memória de meu pai, Laerte. 


\section{AGRADECIMENTOS}

Ao professor Dr. Marcelo Augusto Leal Alves, pela orientação e constante estímulo transmitido durante todo o trabalho.

À minha família. Minha esposa, Clarice, minha mãe, Elvira, e minha irmã, Vivian, pela paciência e apoio demonstrados.

Aos amigos e todos que colaboraram direta e indiretamente na execução deste trabalho. 
Que Deus me conceda falar conforme desejo, e ter pensamentos dignos dos dons que recebi.

Pois é ele o guia da Sabedoria e o que corrige os sábios.

Em suas mãos estamos nós e nossas palavras, assim como toda prudência e habilidade.

( Sb 7, 15-16) 
Este estudo apresenta uma investigação sobre a possibilidade de adotar o processo de solda por agitação e fricção, ou "friction stir welding" em substituição ao processo usual de fixação por rebitagem, na construção de um painel de fuselagem aeronáutica de dimensões compatíveis com uma aeronave regional com capacidade aproximada de cinqüenta assentos. A investigação avalia aspectos técnicos de engenharia, tais como capacidade de unir materiais heterogêneos, resistência mecânica, vida em fadiga da estrutura, aspectos de produtividade e custos associados. O processo de solda por agitação e fricção ocorre em estado sólido, não requer a introdução de um terceiro material ou qualquer tipo de arco elétrico ou atmosfera de gás inerte. Os materiais a serem unidos não atingem o ponto de fusão, mas são submetidos à severa deformação plástica, sendo misturados sem que haja fusão. As características mecânicas resultantes dos componentes soldados são equivalentes ou superiores às características dos componentes rebitados. Sob o ponto de vista econômico, existem ganhos em redução de custos de mão de obra e aumento na velocidade de produção, quando comparado ao processo de rebitagem. 


\section{ABSTRACT}

This study presents an investigation about the possibility of use friction stir welding process to replace the usual riveting process to build an aeronautic fuselage panel which has its dimensions compatible to a fifty seats regional aircraft. The investigation evaluates engineering technical aspects as the capability to join dissimilar materials, the mechanical strength, structure's fatigue life, productivity aspects and associated costs. Friction stir welding is a solid state process where a third material deposition is not required, as well is not required any electric arc or inert gas atmosphere. The materials to be joined do not reach the fusion point, but are subjected to severe plastic deformation, being mixed without melting. The mechanical behavior of welded components is equivalent or better than the behavior of riveted components. From financial standpoint, there are benefits on labor costs reduction and increased production rate, when compared to the riveting process. 


\section{LISTA DE ILUSTRAÇÕES}

Figura 1. Principio do processo Friction Stir Welding

Figura 2. Ferramenta FSW e seção de solda de $75 \mathrm{~mm}$ de espessura

Figura 3. União entre placas de Alumínio e Aço

Figura 4. Exemplos de projetos de ponta e ombro de ferramentas FSW

Figura 5. Ferramenta desenvolvida por

TWI - The Welding Institute 26

Figura 6. Ferramentas desenvolvidas por

TWI - The Welding Institute

Figura 7. Protótipo de ferramenta para processo FSW

Figura 8. Perfil geral de juntas de topo unidas por Friction Stir Welding

Figura 9 - Fuselagem da aeronave Boeing 747

Figura 10 - Curvas características das propriedades mecânicas do material AA2024

Figura 11 - Curva característica de dureza do material AA6082 após solda FSW

Figura 12 - Curva característica de dureza do material AA6061 após solda FSW

Figura 13 - Curva característica de dureza do material 
Figura 14 - Curva característica de dureza do material AA6061 após solda FSW

Figura 15 - Curva característica de dureza do material AA5083 após solda FSW

Figura 16 - Curva característica de dureza do material AA2024 após solda FSW

Figura 17 - Curva característica de dureza do material AA7074 após solda FSW

Figura 18 - Curva característica de dureza do material AA7074 após solda FSW

Figura 19 - Curvas de Tensão x Deformação dos materiais AA7075, AA2024 e da união entre AA2024 com AA7075 por FSW

Figura 20 - Curva de Tensão x Deformação da união entre AA2024 com AA7075 por FSW, na região do núcleo

Figura 21 - Curva de fadiga dos materiais AA2024, AA7075 e da união entre os materiais AA2024 e AA7075, relacionando número de ciclos e amplitude de esforços

Figura 22 - llustração do painel padrão utilizado para o estudo desenvolvido por Widener $\mathrm{C}$.

Figura 23 - Ensaio de tensão para painéis enrijecidos Materiais AA7075-T6 e AA2024-T3, unidos pelos processos FSW e Rebitagem 
Figura 24 - Comparação entre ensaios de cisalhamento para painéis rebitados e unidos por FSW

Figura 25 - Falha em painéis unidos por FSW e por rebites, sujeitos aos mesmos esforços 


\section{LISTA DE TABELAS}

Tabela 1 - Características mecânicas dos materiais, conforme classificação AA -

The Aluminum Association - EUA

Tabela 2 - Material AA 2024 - Consolidação

dos dados apresentados por Khaled

Tabela 3 - Material AA 7075 - Consolidação

dos dados apresentados por Khaled

Tabela 4 - Propriedades mecânicas das uniões

entre materiais AA2024 e AA7075, comparadas

com as propriedades dos materiais base 
SUMÁRIO

1- Introdução

3 - Descrição do Processo de Soldagem

por Agitação e Atrito - FSW

24

4 - Características Mecânicas da união de

Materiais das séries AA2024 e AA7075 pelo

processo FSW, e sua adequação ao emprego

na indústria aeronáutica.

4.1 - Resistência Mecânica

4.2 - Solda de ligas Heterogêneas de Alumínio

4.3 - Resistência das uniões rebitadas

4.4 - Comparativo entre eficiência dos processos de união por FSW e por rebites.

4.5 - Comportamento mecânico de uniões entre materiais AA2024 e AA7075 soldadas por FSW.

4.6 - Comparativo entre comportamento mecânico de painéis soldados por FSW e painéis rebitados.

5 - Comparação entre painéis manufaturados com longarinas rebitadas e com longarinas soldadas por FSW

5.1 - Produtividade 
6 - Efeitos da construção de aeronaves

com painéis formados por FSW na

manutenção e operação

54

7 - Conclusões

56 


\section{1- Introdução}

Friction Stir Welding ( FSW ) é um processo de soldagem adequado ao uso em materiais metálicos, que atua através da deformação plástica dos mesmos, sem que os materiais atinjam ponto de fusão. O processo ocorre sem a deposição de um terceiro material diferente dos materiais a serem unidos, como é comum em outros processos de soldagem.

Este processo foi criado por um instituto Britânico, de nome The Welding Institute ( TWI ), sendo particularmente adequado à união de ligas de alumínio.

No presente estudo traduziremos o nome do processo de Friction Stir Welding para Solda por Agitação e Friç̧ão. Pesquisando a literatura técnica nacional não encontramos uma tradução estabelecida anteriormente por outros autores, que fosse conflitante com a tradução proposta, portanto a adotaremos neste trabalho.

No processo FSW, a união dos metais ocorre em estado sólido, e, desta forma não está associado aos maiores problemas de soldabilidade, tais como formação de porosidade ou trincas de solidificação, observadas em ligas endurecidas de alumínio, como as ligas das séries AA 2XXX e AA 7XXX, amplamente utilizadas na construção de estruturas aeronáuticas.

As ligas das séries AA 2XXX e AA 7XXX, são ligas de alumínio que possuem cobre e zinco em sua composição, respectivamente, recebendo esta classificação conforme associação norte-americana "The Aluminum Association ".

As vantagens do processo FSW aparecem em aplicações de alta produção, devido ao seu custo inicial relativamente elevado. Os custos de produção do processo FSW são significativamente menores que os custos de solda por fusão. [2]

A resistência mecânica da solda obtida pelo processo FSW é de $30 \%$ a $50 \%$ mais elevada que a obtida pelo processo de solda por arco, e a vida em fadiga obtida é similar ou superior à obtida em painéis rebitados. [3] 
Adicionalmente, o processo FSW permite a união de ligas antes consideradas imprópria para soldagem e também permite a união de materiais heterogêneos sem incorrer em problemas de corrosão.[4]

Projetistas e construtores de aeronaves hoje avaliam a viabilidade de um processo produtivo de fuselagem que utilize a tecnologia de solda por agitação e fricção FSW em substituição ao tradicional método de união de componentes pelo processo de rebitagem, principalmente na construção de aeronaves das categorias VLJ ( very light jet ) e LJ ( light jet ).

As aeronaves das categorias VLJ e LJ representam um novo nicho de mercado, onde aeronaves com capacidade entre 4 e 8 assentos, além da tripulação, seriam adquiridas por indivíduos ou empresas, para uso dedicado ou como táxi aéreo, sendo destinadas a transporte individual ou de pequenos grupos.

As aeronaves desta categoria devem ter custo reduzido, e devem ser produzidas em cadência acelerada para os padrões da indústria aeronáutica.

Uma empresa que está sendo pioneira na utilização do processo FSW para construção de aeronaves da categoria VLJ, é a empresa norte americana Eclipse Aviation. Seu plano de negócios prevê uma cadência de aproximadamente 1500 aeronaves por ano, utilizando FSW como método de fixação de elementos estruturais da fuselagem.

Atualmente, empresas dedicadas à produção de jatos executivos têm produção em níveis próximos aos milhares de aeronaves por ano, como, por exemplo, a também norte americana Cessna, que tem produção anual de aproximadamente 900 aeronaves.

Para estes níveis de produção, a introdução do processo FSW pode resultar em redução de custo e aumento velocidade, e, justificar um investimento inicial em máquinas e equipamentos.

Outro aspecto positivo da aplicação da tecnologia FSW reside na redução do peso da aeronave. Com os crescentes custos do combustível de aviação, redução de 
peso significa redução de custos operacionais para aeronaves das categorias regional e de longo alcance, o que também pode justificar o investimento inicial de produção.[4]

Do ponto de vista técnico, o processo FSW traz melhorias nas características de resistência mecânica, resistência à fadiga e à corrosão das uniões, quando comparadas com o processo de rebitagem.

As superfícies formadas são livres de vazamentos de fluidos, o que se aplica a áreas estanque, como por exemplo os tanques de combustível localizados nas asas, onde os rebites de união entre as chapas externas e estrutura interna da asa devem ser vedados individualmente com materiais selantes, que além de adicionarem peso, tem baixa confiabilidade, e exigem manutenção constante.

Nas demais áreas da aeronave, onde a vedação de fluidos não é necessária surge, no caso de uniões rebitadas, a possibilidade de corrosão nos furos, já que podemos ter materiais heterogêneos em contato, sujeitos ao acúmulo de umidade. Os métodos de proteção para uma condição como esta exigem aplicação de produtos químicos, encarecendo e dificultando o processo produtivo e de manutenção.[4]

O objetivo do trabalho proposto será o de investigar a tecnologia existente para o processo FSW, avaliar sua adequação sob o ponto de vista técnico, avaliar a viabilidade econômica e os impactos operacionais de se utilizar esta nova tecnologia, em substituição ao processo de rebitagem, para fixação de um determinado componente estrutural utilizado na construção de aeronaves de transporte regional civil, com capacidade aproximada de cinqüenta passageiros.

Para esta avaliação definiu-se um painel padrão, com as características dimensionais e estruturais aproximadas de um painel utilizado na construção de aeronaves regionais de médio porte, para o qual, o custo de produção, utilizando-se os processos de rebitagem e o processo por solda FSW para fixação de elementos estruturais é comparado.

No processo tradicional de construção aeronáutica, o rebite atua como prendedor mecânico. Antes de ser instalado pode ser descrito como um eixo cilíndrico com uma 
cabeça em uma das extremidades. Após sua instalação em um furo pré-usinado que atravessa as partes a serem unidas, tem sua parte traseira deformada plasticamente, expandindo-se até aproximadamente 1,5 vezes o diâmetro original do eixo, fixando o rebite.

Uma vez instalado, o rebite é capaz de suportar principalmente cargas de tensão, não sendo adequado para suportar cargas de cisalhamento, que são relevantes nas estruturas aeronáuticas.

As uniões rebitadas são adequadas para construção de estruturas submetidas a esforços cíclicos, e para unir elementos de metais de difícil soldagem, razão pela qual até o momento utiliza-se largamente este processo para a união de elementos de construção aeronáutica, onde existe a predominância do uso de ligas de alumínio, material de difícil soldagem pelos processos tradicionais.

O processo de solda por atrito e fricção, FSW, é um processo de união em estado sólido, onde as características originais dos materiais unidos sofrem pouca variação em relação aos materiais originais.

No processo FSW, uma ferramenta cilíndrica com um pino e um ombro é inserida entre os materiais a serem unidos, de forma que o pino seja de comprimento aproximadamente igual à espessura dos materiais, e o ombro forneça pressão sobre os mesmos. A ferramenta possui movimento de rotação em torno de seu eixo longitudinal e movimento de translação com trajetória que definirá a linha de união entre os materiais.

O contato entre a ferramenta de soldagem FSW e os materiais das peças a serem unidas gera calor por fricção, causando elevação da temperatura dos materiais a ponto de reduzir sua resistência a deformações mecânicas, sem que os mesmos atinjam o ponto de fusão, mas permitindo o deslocamento da ferramenta, inserida nos materiais, pela linha de solda desejada, devido à severa deformação plástica ocorrida na região.

A natureza de estado sólido do processo FSW permite obter resultado que apresenta algumas características vantajosas sobre os métodos de solda por fusão, 
tais como a inexistência de porosidade ou trincas, resultantes da solidificação dos materiais. De forma geral o processo de solda FSW produz baixa concentração de defeitos, sendo tolerante a grandes variações de parâmetros do processo. 


\section{2 - Revisão Bibliográfica}

$\mathrm{Na}$ pesquisa bibliográfica executada para elaboração desta trabalho, não foram encontradas publicações que tratassem diretamente sobre o tema abordado.

A fase inicial de pesquisa concentrou-se em publicações que mostram os aspectos gerais da tecnologia de solda por agitação e fricção, FSW, e a fase final concentrouse em pesquisar sobre os efeitos da solda por FSW nas características mecânicas dos materiais a serem unidos e à avaliação dos efeitos na resistência das estruturas unidas por FSW.

Nos trabalhos de Wittman, Pires e Brandi [1] e de Kallee, Nicholas e Thomas [9] são apresentadas visões genéricas sobre o processo FSW, sobre o estado de desenvolvimento da tecnologia para ligas diversas de alumínio e para outros materiais, metálicos e plásticos, bem como perspectivas de aplicação.

As publicações de DeFalco [2], Mendez e Eagar [3] e Irving [4] apresentam comparativos entre os processos de soldagem, tais como solda por resistência, solda a arco, plasma, laser, feixe de elétrons e FSW, aplicados atualmente à aviação, e apresentam histórico que indica as razões pelas quais o processo de rebitagem é predominante até o momento na indústria de construção aeronáutica.

O trabalho dos autores Norman, Brough e Prangnell [5] investiga a estrutura metalográfica de uma liga de alumínio AA 2024 sujeita à união por FSW. Esta é uma das ligas consideradas neste estudo.

Em sua tese de doutorado, Muller [7] apresenta investigação experimental e analítica do comportamento à fadiga de uma fuselagem unida por rebites.

No trabalho apresentado por Widener [11], pode-se encontrar estudo comparativo sobre a resistência de painéis manufaturados pelos processos de rebitagem e soldagem FSW, e uma avaliação das características de corrosão.

A estrutura, as propriedades dos elementos soldados por FSW, e, os fatores de processo que os influenciam, são apresentados nos trabalhos dos autores Reynolds, 
Tang, Gnaupel-Herold e Prask [12] ; Luan, Wang, Yajuan e Chenbin [13] ; Wang, Shuhua e Zhaoxia [14] ; Attallah e Salem [15] ; Lee e Jung [16] ; Cederqvist e Reynolds [17] ; Fonda, Bingert e Colligan [18] e Cederqvist [19].

Midling [20] apresenta estudo sobre o processo de fabricação de painéis de alumínio unidos por FSW.

Khaled [21] apresenta revisão de diversos trabalhos relativos às características mecânicas das uniões por FSW para diversas ligas de alumínio.

O fluxo do material durante o processo de união por FSW é apresentado no trabalho de Colligan [26], e um modelo matemático para transferência de calor no processo é apresentado no trabalho de Song e Kovacevic [30].

Um modelamento de custos para construção de aeronaves é apresentado por Curran, Price, Raghunathan, Bernard, Crosby, Castagne e Mawhinney [27].

O comportamento das uniões por FSW, com relação à fadiga e à corrosão, são estudados por Sharma e Mishra [32], bem como por Park e outros [31].

Ericsson e Sandstrom [34] estudaram a influência da velocidade de soldagem no comportamento de uniões por solda FSW e comparam com as uniões por solda MIG e TIG.

Os aspectos relativos a tensões residuais e às propriedades da zona afetada pelo calor durante a solda na propagação de trincas de fadiga para a liga AA 2024, são apresentadas nos trabalhos de Bussu e Irving [35] e também no trabalho de Jata [40]. Os aspectos relativos à corrosão e proteção das soldas FSW são apresentados por Davenport e outros [39] e também por Burford, Widener e Tweedy [46].

O comportamento de ligas AA 2024 e AA 7075 unidas por FSW à compressão dinâmica é estudado por Chao e Miller [43], e um modelo em elementos finitos que avalia os efeitos de temperaturas elevadas e de deformações, nas características mecânicas de painéis soldados por FSW, é apresentado por Murphy, Price e Curran [42]. 
Em Cavaliere, Cerri e Squilla [48], é apresentado estudo que avalia a resposta mecânica de ligas AA 2024 e AA 7075, unidas por FSW.

Em sua dissertação de mestrado, Rosato [ 49] apresenta dados de produtividade dos processos de rebitagem e de FSW, que foram utilizados no capítulo deste trabalho relativo à viabilidade econômica do processo FSW para produção de painéis aeronáuticos. 


\section{3 - Descrição do Processo de Soldagem por Agitação e Atrito - FSW}

Neste capítulo pode-se encontrar uma descrição do processo de soldagem por agitação e atrito - FSW , exemplos ilustrados de ferramentas adequadas ao processo, classificação das diferentes regiões que possuem características metalúrgicas próprias, formadas na interface entre os materiais unidos pelo processo FSW devido aos esforços mecânicos e efeitos térmicos gerados no processo. Estão ainda listados neste capítulo, parâmetros que afetam a qualidade e a produtividade das uniões soldadas pelo processo FSW.

Friction Stir Welding é uma técnica de estado sólido onde uma ferramenta rotatória, dotada de movimento de translação corre ao longo de uma linha de contato entre os materiais a serem soldados, criando uma união integral através de severa deformação plástica do material afetado pela ferramenta [5].

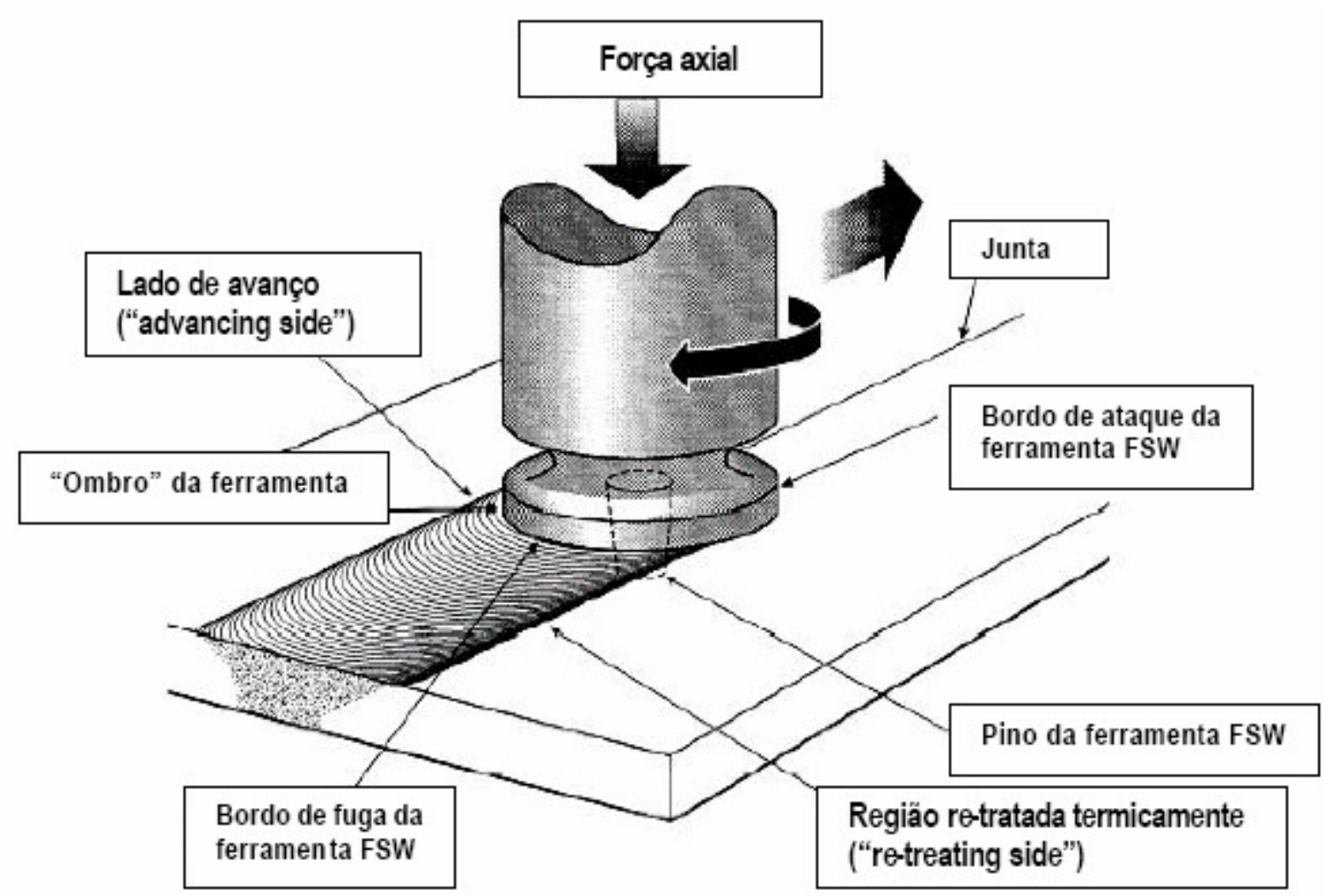

Figura 1. Principio do processo "Friction Stir Welding"[49] 


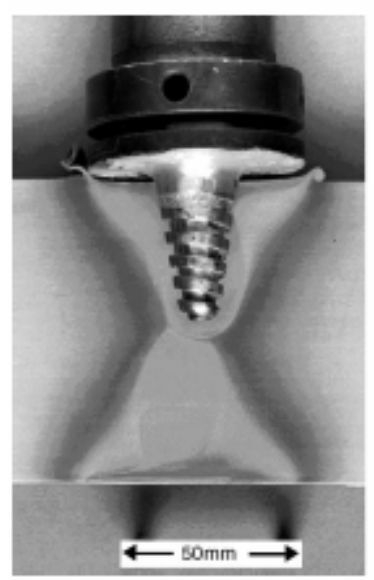

Figura 2. Ferramenta FSW e seção de solda de 75 mm de espessura [9]

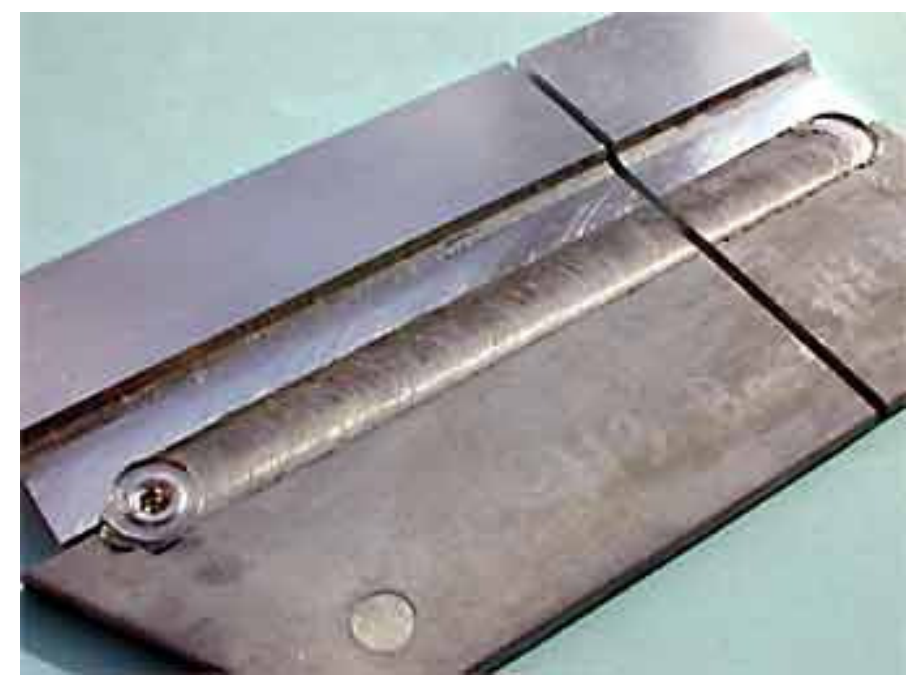

Figura 3. União entre placas de Alumínio e Aço [9]

Nas figuras 1, 2 e 3, pode-se ver, respectivamente, uma descrição esquemática do processo, observar um corte ilustrativo da região da solda com a ferramenta inserida nos materiais e uma imagem de duas placas de materiais diferentes unidos por FSW.

A ferramenta consiste em um pino de pequeno diâmetro, que normalmente possui rosca, e um ombro de diâmetro maior, que trabalha alinhado no mesmo plano dos materiais a serem unidos, e restringe o material deformado às dimensões do materiais base, formando pressão que consolida a junta.[5], [46] 
A terminologia "ombro" da ferramenta aparece anteriormente na literatura, no texto da referência [49], e foi mantida neste trabalho.

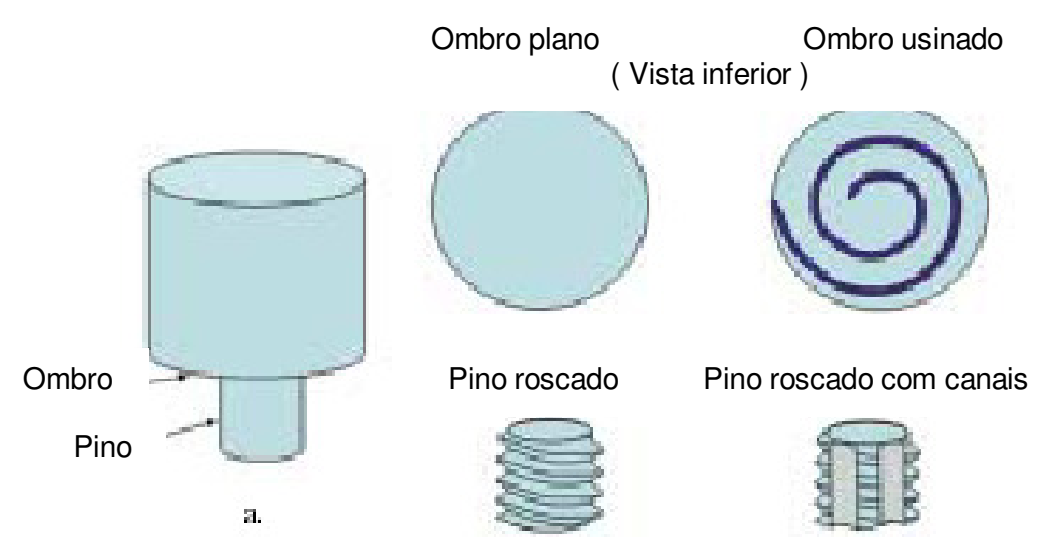

Figura 4. Exemplos de projetos de ponta e ombro de ferramentas FSW [Mishra, R.S.

- Materials Science and Engineering R 50 ( 2005 )].

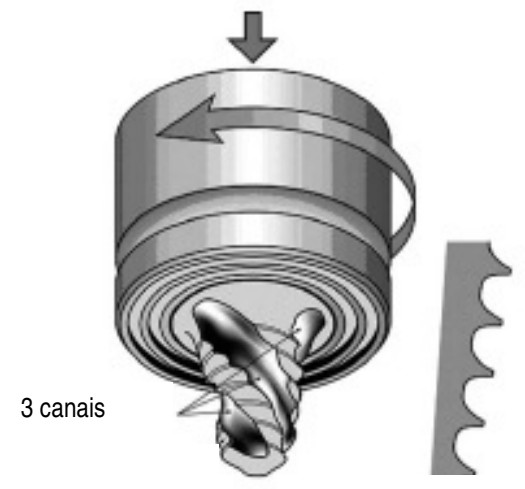

Figura 5. Ferramenta desenvolvida por TWI - The Welding Institute, Reino Unido 2001 [Mishra, R.S. - Materials Science and Engineering R 50 ( 2005 ) ] 


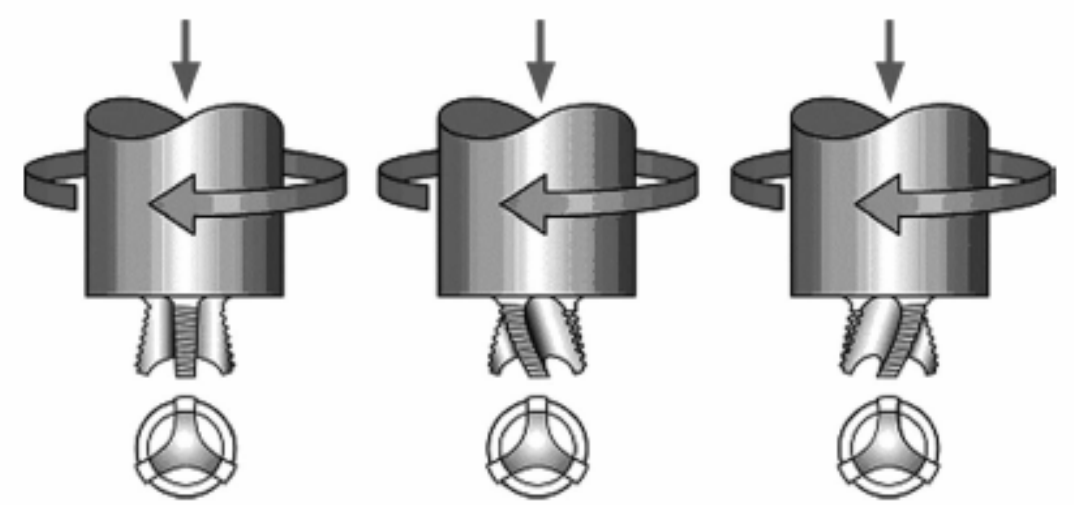

Figura 6. Ferramentas desenvolvidas por TWI - The Welding Institute, Reino Unido [Mishra, R.S. - Materials Science and Engineering R 50 ( 2005 )]

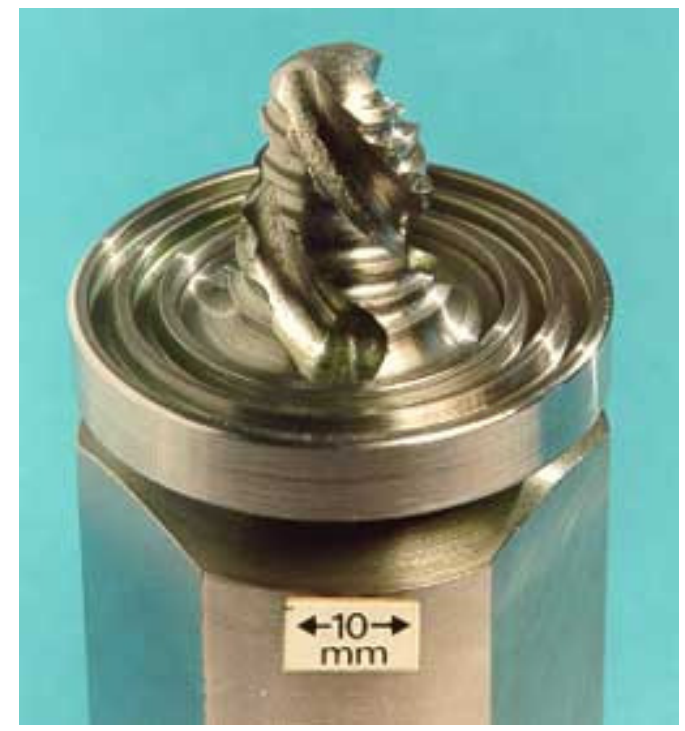

Figura 7. Protótipo de ferramenta para processo FSW [9]

Nas figuras 4, 5, 6 e 7 podem-se ver alguns exemplos de ferramenta para soldagem pelo processo $\mathrm{FSW}$.

A ferramenta rotatória aquece o material por uma combinação de fricção e trabalho 
plástico de deformação a temperaturas próximas porém inferiores ao ponto de fusão dos materiais base. [5]

O fluxo dos materiais é complexo e depende do projeto da ferramenta, todavia, a maior parte da deformação é causada por cisalhamento do material em torno da mesma. [5]

Devido ao movimento de translação, o metal é transferido da zona frontal para a zona traseira do pino, onde o mesmo é forjado. [5], [46]

Nas ligas de alumínio, FSW pode produzir até quatro zonas microestruturais distintas: [21]

Zona 1 - " Nugget " no centro da solda, próximo ao local de passagem do pino, onde normalmente existem grãos finos recristalizados. O termo em português para " nugget “ mais aproximado é a palavra grão, todavia, para evitar conflito com a mesma palavra utilizada em metalurgia com outro significado, optou-se neste texto por manter o termo em inglês.

Zona 2 - Área de contato do ombro, onde existe zona de deformação com grande área e pouca profundidade.

Zona 3 - Região Termomecânicamente afetada, imediatamente próxima à zona do “ Nugget ", onde o material não foi cisalhado diretamente pela ferramenta, mas ainda assim, se deformou pela sua passagem .

Zona 4 - Zona afetada termicamente, possui degradação termal, mas não foi plasticamente deformada. 


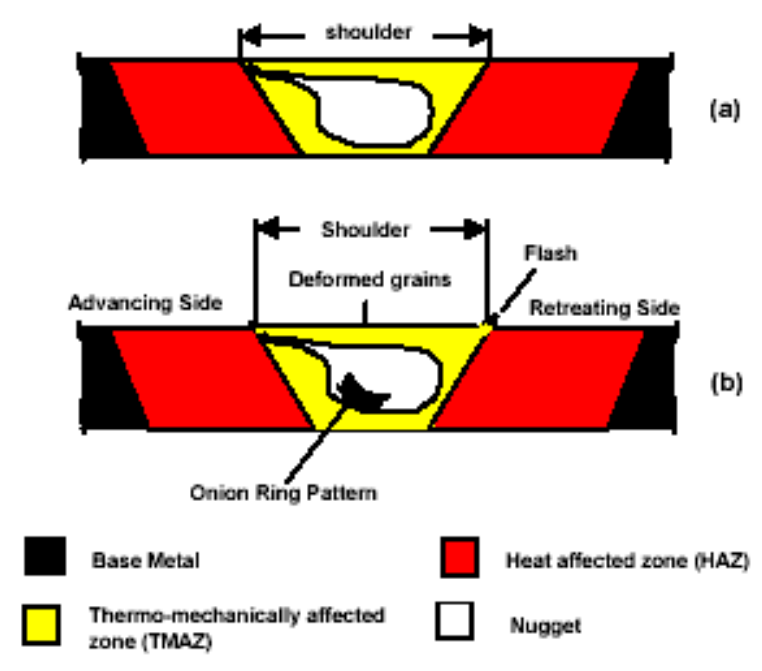

Figura 8. Perfil geral de juntas de topo unidas por Friction Stir Welding [21]

Os termos escritos em inglês na figura 8 são traduzidos no presente texto como:

"Shoulder ": Ombro

"Deformed grains “: Grãos deformados

"Advancing Side ": Lado de avanço ( da ferramenta )

"Retreating side ": Lado de fuga ( da ferramenta)

"Flash " : Rebarba

"Onion Ring Pattern " : Perfil de anéis circulares

"Base Metal ": Material base

“ Termo-mechanically affected zone " : Zona afetada termo-mecânicamente

" Heat affected zone ": Zona afetada pelo calor

Vários parâmetros afetam a qualidade e a produtividade das uniões soldadas pelo processo FSW, tais como:

- Velocidade de rotação da ferramenta

- Velocidade de translação da ferramenta

- Força axial

- Inclinação da ferramenta com relação ao plano da solda

- Diâmetro do ombro da ferramenta

- Relação entre os diâmetros do pino e do ombro da ferramenta

- Capacidade de troca de calor entre as peças a serem soldadas e a base de fixação 
As características do processo FSW indicam a necessidade de um equipamento para soldagem similar a uma máquina fresadora, porém com um dispositivo que imprima força vertical na ferramenta, de forma a manter a pressão sobre a área de solda.

Com a disponibilidade de máquinas fresadoras que possuem trajetória da ferramenta controlada por comando numérico ( CNC ), entende-se que a solda por FSW é adequada para fixação de elementos que tenham sua união garantida por cordões de solda lineares ou não, tanto bidimensionais quanto tridimensionais.

Os painéis aeronáuticos atuais são formados por elementos metálicos, e o perfil se união de seus componentes, em sua maioria, é bidimensional, com alguns elementos que exigiriam percurso tridimensional da ferramenta.

Desta forma, o processo FSW sob o ponto de vista de execução da solda, mostra-se viável à produção de painéis aeronáuticos. 


\section{4 - Características Mecânicas da união de Materiais das séries}

\section{AA2024 e AA7075 pelo processo FSW, e sua adequação ao} emprego na indústria aeronáutica.

Neste capítulo é feito comparativo entre as características de resistência mecânica apresentadas por materiais utilizados na construção de estruturas aeronáuticas, utilizando-se os processos de união por fricção e agitamento ( FSW ) e de rebitagem.

\section{1 - Resistência Mecânica}

As uniões por solda FSW produzem pequenas alterações de características mecânicas em relação aos materiais originais quando comparadas a uniões por outros tipos de solda.

A elevada resistência mecânica apresentada, e os bons índices de alongamento dos materiais soldados em relação ao material base é consistente com a observação da existência de grão refinados na região central da solda, referida neste texto como nugget.

Na construção típica de aeronaves utiliza-se, para a região da fuselagem, os elementos "Stringers ", "Frames "e "Skin ", que neste trabalho traduziremos como " Longarinas ", "Cavernas "e "Chapas ". 


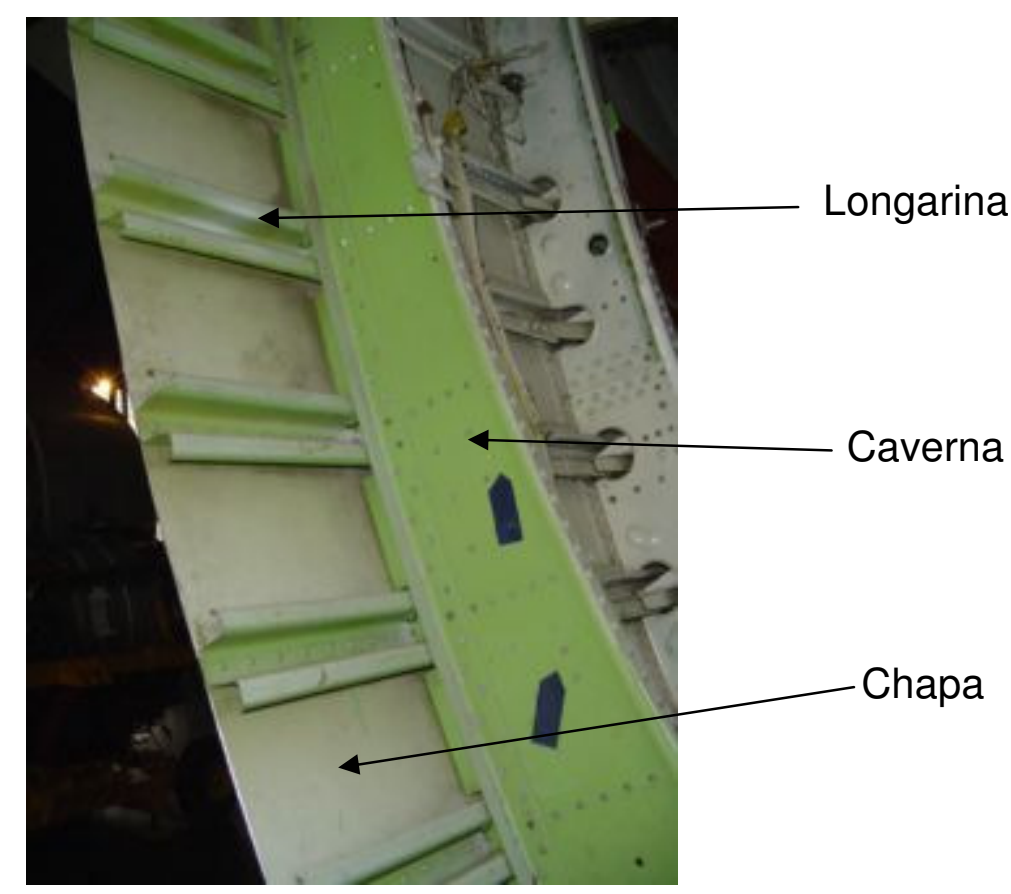

Figura 9 - Fuselagem da aeronave Boeing 747 - [50]

As longarinas geralmente são formadas por perfis extrudados de alumínio da série AA $7 X X X$, e, são conectadas às chapas. As longarinas suportam cargas axiais induzidas pelos momentos fletores atuantes na fuselagem.

As cavernas são formadas por chapas conformadas em perfil " $U$ ", de material alumínio, também da série $A A 7 X X X$, e se conectam as chapas. As cavernas recebem e transmitem cargas concentradas e reduzem vão livre entre as longarinas, colaborando para a estabilidade estrutural da fuselagem.

As chapas são feitas de alumínio da série $A A$ 2XXX e estão sujeitas cargas de cisalhamento causado por forças externas transversais e torsionais, suportando também tensões devidas à pressurização da cabine.

Para a avaliação a que se propõe o presente estudo, vamos considerar a produção de um painel padrão com as características descritas no desenho 1, utilizando-se o processo de solda por FSW em lugar da união por rebites entre as longarinas e as chapas, verificando sua adequação técnica, comparando os custos de produção. 
Para união das cavernas com as chapas será considerado o processo de rebitagem.

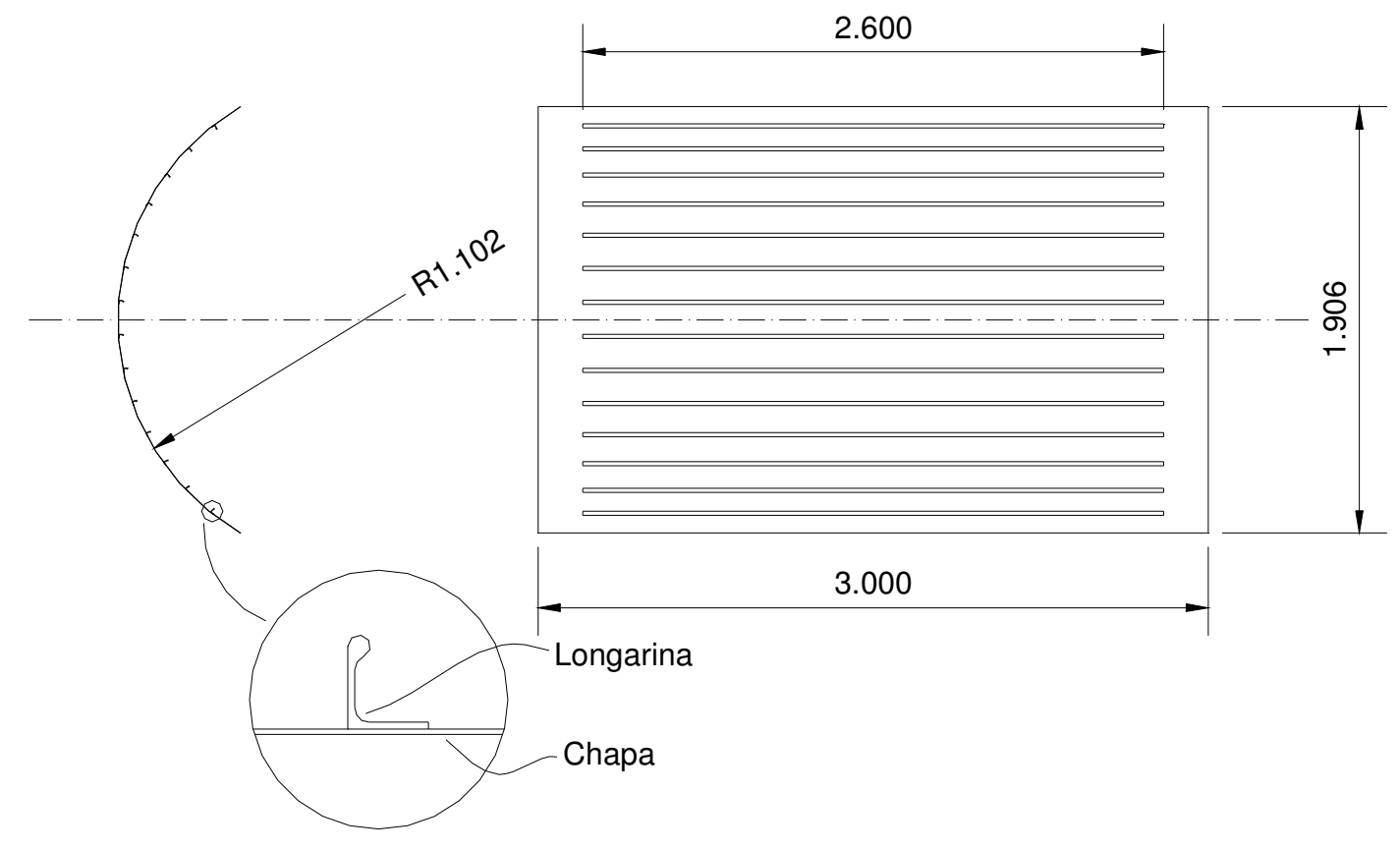

Desenho 1 - ( dimensões em $\mathrm{mm}$ )

- Características relevantes do painel padrão :
- Quatorze linhas de longarinas
- Cento e trinta rebites por linha de longarinas
- Inexistência de janelas
- Material das longarinas: AA $2024-1,2 \mathrm{~mm}$ de espessura
- Material das chapas: AA $7075-1,6 \mathrm{~mm}$ de espessura 
As características mecânicas dos matérias base considerados na construção do painel padrão encontram-se apresentadas na tabela 1 :

\begin{tabular}{|l|l|l|}
\hline \multicolumn{2}{|c|}{ AA 2024 } & AA 7075 \\
\hline Tensão de escoamento & $76 \mathrm{Mpa}$ & $95 \mathrm{Mpa}$ \\
\hline Tensão de ruptura & $185 \mathrm{Mpa}$ & $220 \mathrm{Mpa}$ \\
\hline Alongamento & $20 \%$ & $17 \%$ \\
\hline Dureza & $47 \mathrm{HB} 500$ & $60 \mathrm{HB} 500$ \\
\hline Tensão de cisalhamento & $125 \mathrm{Mpa}$ & $150 \mathrm{Mpa}$ \\
\hline Tensão limite de fadiga & $90 \mathrm{Mpa}$ & $160 \mathrm{Mpa}$ \\
\hline
\end{tabular}

Tabela 1 - Características mecânicas dos materiais, conforme classificação AA - The Aluminum Association - EUA [51]

Conforme pesquisa feita por Khaled [21], vários autores levantaram as propriedades mecânicas dos materiais AA 2024 e AA 7075 sujeitos ao processo de solda FSW. Os resultados encontrados são mostrados nas tabelas 2 e 3 :

\begin{tabular}{|c|c|c|c|c|c|c|}
\hline AA 2024 & $\begin{array}{c}\text { Hashimoto } \\
\text { et al }\end{array}$ & $\begin{array}{c}\text { Von } \\
\text { Strombeck } \\
\text { et al }\end{array}$ & $\begin{array}{c}\text { Biallas } \\
\text { et al }\end{array}$ & $\begin{array}{c}\text { Talwar } \\
\text { et al }\end{array}$ & $\begin{array}{c}\text { Zettler } \\
\text { et al }\end{array}$ & $\begin{array}{c}\text { Kumagai } \\
\text { et al }\end{array}$ \\
\hline $\begin{array}{c}\text { Eficiência da } \\
\text { União }\end{array}$ & $78 \%$ & $83 \%$ & $90 \%$ & $88 \%$ & $\begin{array}{c}70 \% \text { a } \\
97 \%\end{array}$ & $83 \%$ \\
\hline $\begin{array}{c}\text { Resistência } \\
\text { a Tração }\end{array}$ & - & $77 \%$ & - & $91 \%$ & - & $79 \%$ \\
\hline $\begin{array}{c}\text { Alongamento } \\
\text { Tensão de } \\
\text { ruptura }\end{array}$ & - & $27 \%$ & $\begin{array}{c}30 \% \text { a } \\
50 \%\end{array}$ & $41 \%$ & - & $19 \%$ \\
\hline $\begin{array}{c}\text { Resitência à } \\
\text { fadiga }\end{array}$ & - & - & - & - & - & - \\
\hline
\end{tabular}

Tabela 2 - Material AA 2024 - Consolidação dos dados apresentados por Khaled [21] 


\begin{tabular}{|c|c|c|c|}
\hline AA 7075 & $\begin{array}{c}\text { Magnusson } \\
\text { e Kallman }\end{array}$ & $\begin{array}{c}\text { Mahoney } \\
\text { et al }\end{array}$ & $\begin{array}{c}\text { Talwar } \\
\text { et al }\end{array}$ \\
\hline $\begin{array}{c}\text { Eficiência da } \\
\text { União }\end{array}$ & $90 \%$ & - & $84 \%$ \\
\hline $\begin{array}{c}\text { Resistência } \\
\text { a Tração }\end{array}$ & - & $80 \%$ & $71 \%$ \\
\hline $\begin{array}{c}\text { Alongamento } \\
\text { ruptura }\end{array}$ & - & $24 \%$ & $33 \%$ \\
\hline $\begin{array}{c}\text { Tensão de } \\
\text { fadiga }\end{array}$ & $\begin{array}{c}\text { Aprox. } \\
\text { Resitência à }\end{array}$ & - & - \\
\hline
\end{tabular}

Tabela 3 - Material AA 7075 - Consolidação dos dados apresentados por Khaled [21]

Os valores apresentados nas tabelas 2 e 3 são dados pela razão entre os valores de resistência mecânica de materiais unidos por FSW em relação ao material base.

As propriedades de resistência mecânica relativas ao material AA 2024 seguem o padrão da curva de dureza, apresentando mínimo na região afetada pelo calor , conforme gráficos da figura 10:
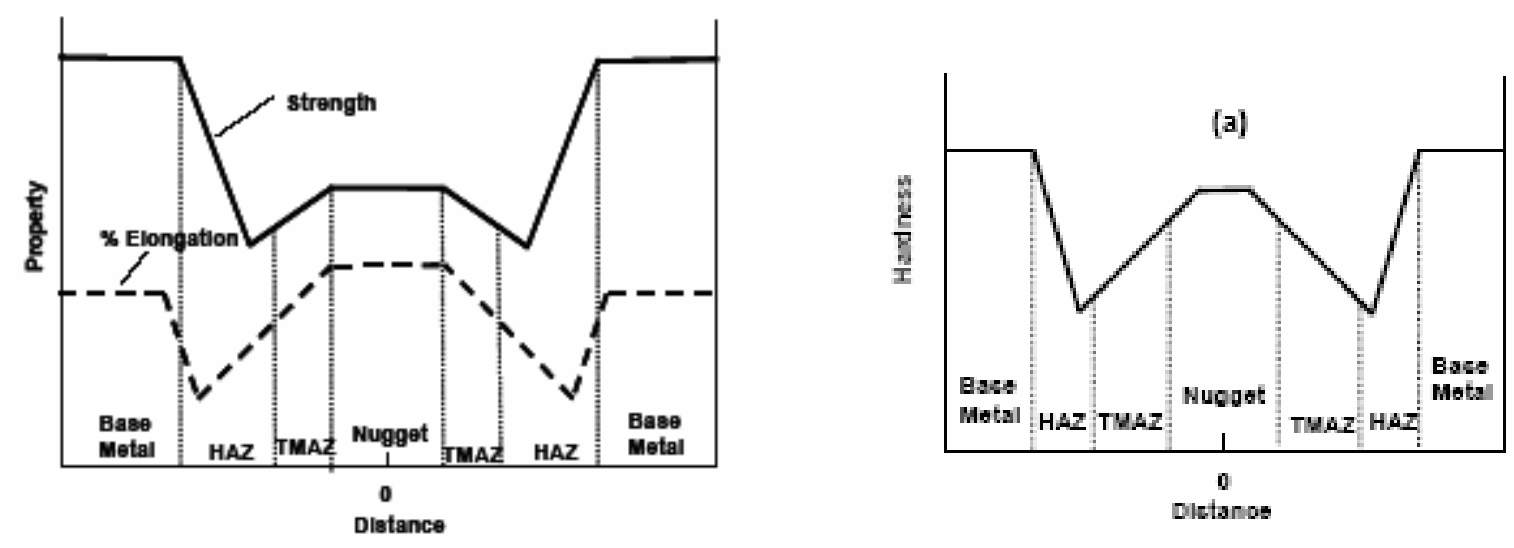

Figura 10 - Curvas características das propriedades mecânicas do material AA2024 - Khaled [21] 
Os termos escritos em inglês na figura 9 são traduzidos no presente texto como:

" Strength " : Resistência ( mecânica )

"Elongation " : Alongamento

"Hardness " : Dureza

“ Distance " : Distância

As propriedades de alongamento seguem curva diferente da dureza, pois apesar de terem mínimo na zona afetada pelo calor, tem seu máximo com valor superior ao do material base, na região do " nugget “.

\section{2 - Solda de ligas Heterogêneas de Alumínio}

Conforme descrito por Khaled [21] os autores Larsson et al e Ouyang e Kovacevic estudaram a solda dos materiais AA 5083 x AA 6082 e AA 6061 x AA 2024, respectivamente, e puderam verificar que a curva de dureza na região da solda sofre variações significativas na região próxima do centro da solda (nugget), conforme se pode ver nos gráficos das figuras 11 e 12, extraídos do mesmo texto.

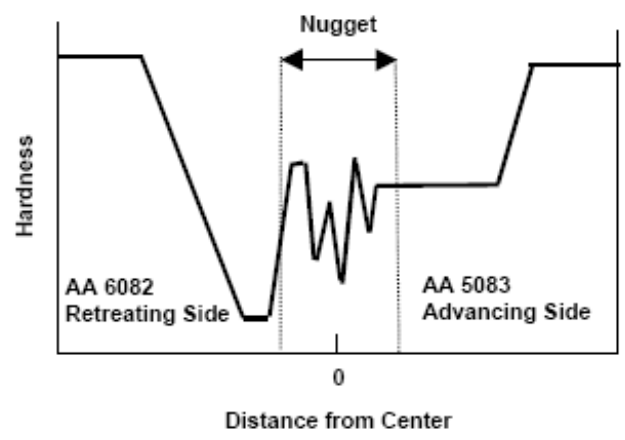

Figura 11 - Curva característica de dureza do material AA6082 após solda FSW - Khaled [21] 


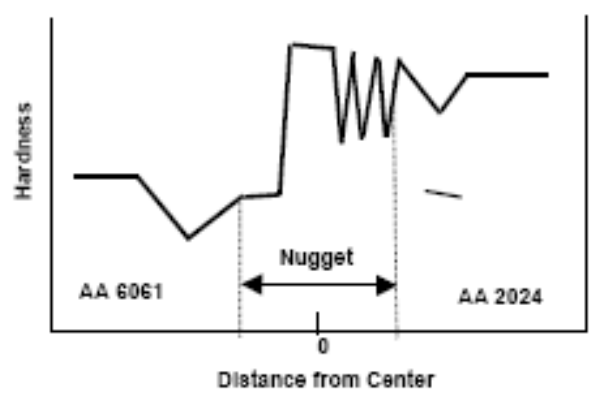

Figura 12 - Curva característica de dureza do material AA6061 após solda FSW - Khaled [21]

O perfil de dureza do material AA 6082 quando soldado ao mesmo material, por FSW, foi estudado pelos autores Hori et al e possui curva similar à apresentada na figura 13:

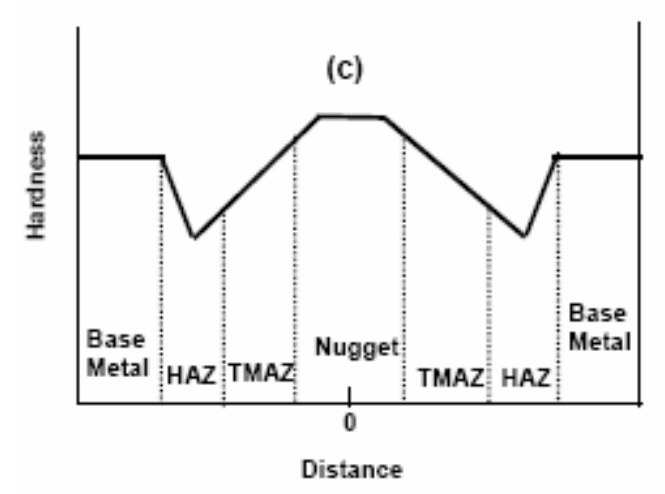

Figura 13 - Curva característica de dureza do material AA6082 após solda FSW - Khaled [21]

O perfil de dureza do material AA 6061 quando soldado ao mesmo material, por FSW, foi estudado pelos autores Linert e Grylls e possui curva similar à apresentada na figura 14: 


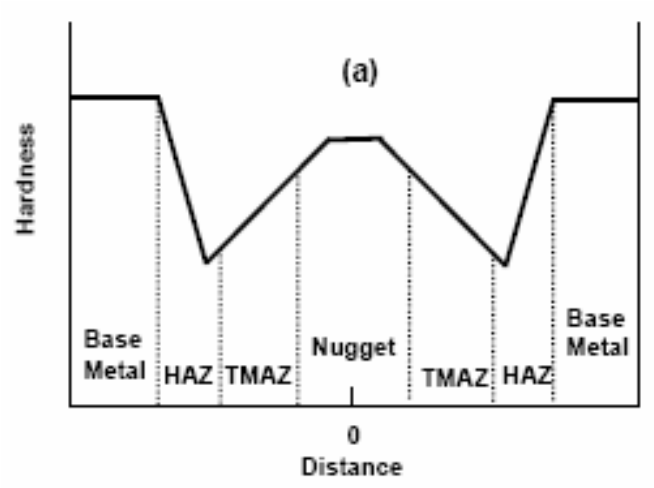

Figura 14 - Curva característica de dureza do material AA6061 após solda FSW - Khaled [21]

O perfil de dureza do material AA 5083 quando soldado ao mesmo material por, FSW, foi estudado pelos autores Colligan et al e possui curva similar à apresentada na figura 15:

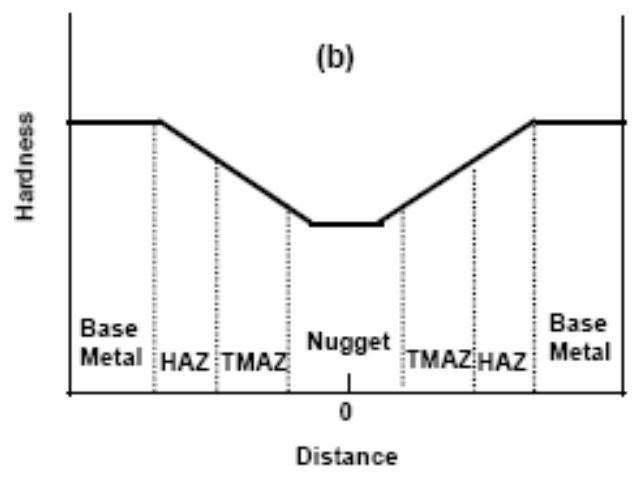

Figura 15 - Curva característica de dureza do material AA5083 após solda FSW - Khaled [21]

O perfil de dureza do material AA 2024 quando soldado ao mesmo material, por FSW, foi estudado pelos autores Zettler et al, Bussu e Irving e Chao et al e apresenta curva similar à apresentada na figura 16: 


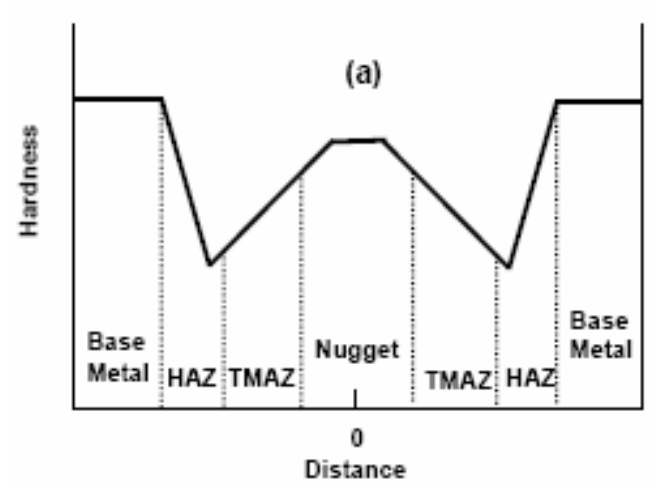

Figura 16 - Curva característica de dureza do material AA2024 após solda FSW - Khaled [21]

O perfil de dureza do material AA 7075 quando soldado ao mesmo material, por FSW, foi estudado pelos autores Shibayanagi e Maeda e Chao et al e apresenta curvas similares às apresentadas nas figuras 17 e 18, respectivamente:

(e)

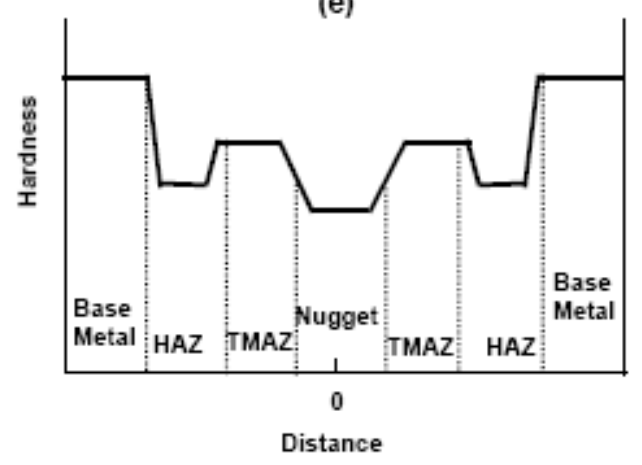

Figura 17 - Curva característica de dureza do material AA7075 após solda FSW , conforme Shibayanagi e Maeda - Khaled [21]

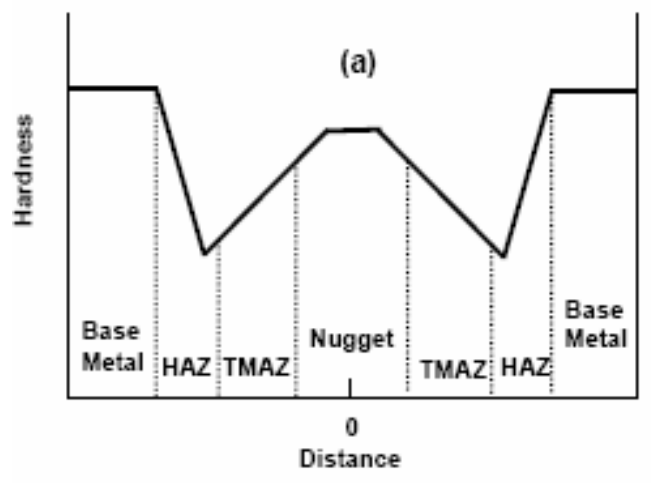

Figura 18 - Curva característica de dureza do material AA7075 após solda FSW , conforme Chao et al - Khaled [21] 


\section{3 - Resistência das uniões rebitadas}

Conforme método de cálculo apresentado na referência [52], capítulo 8, o coeficiente de resistência de uma união rebitada se calcula como:

$$
\begin{aligned}
& \varphi=\mathbf{t}-\mathbf{d} / \mathbf{K ~ t} \text {, onde: } \quad \mathrm{t}=\text { distância entre centro dos rebites } \\
& \text { d= diâmetro do rebite } \\
& \mathrm{K}=\text { coeficiente de concentração de tensões } \\
& \text { ( para uma fileira de rebites, } \mathrm{K}=1 \text { ) }
\end{aligned}
$$

Para linha de rebites onde $t=3 d, \varphi=0,67$ significando redução de $33 \%$ na resistência dos elementos a unir.

Na construção de aeronaves, os valores típicos encontrados para união rebitada das longarinas nas chapas de fuselagem são $d=3 \mathrm{~mm}$ e $t=20 \mathrm{~mm}$, de onde se pode calcular o coeficiente $\varphi=0,85$.

\section{4 - Comparativo entre eficiência dos processos de união por FSW e por rebites.}

Conforme os diversos estudos citados nas tabelas 2 e 3 , a eficiência da união de materiais AA 2024 e AA 7075 situa-se entre $70 \%$ e 97\% do material base, dependendo de parâmetros de processo.

As uniões rebitadas, em sua utilização típica para união de longarinas e chapas de fuselagem aeronáutica possuem eficiência da ordem de $85 \%$

Desta forma, as uniões através do processo FSW, sendo produzidas com parâmetros adequados de processo, podem apresentar eficiência estrutural comparável às uniões rebitadas. 
4.5 - Comportamento mecânico de uniões entre materiais AA2024 e AA7075 soldadas por FSW.

Conforme estudo de P. Cavaliere e outros [48], as uniões entre os materiais AA2024 e AA7075, soldadas pelo método FSW, possuem características mecânicas similares ao materiais base menos resistente, como se pode ver na tabela abaixo:

Tabela 4 - Propriedades mecânicas das uniões entre materiais AA2024 e AA7075, comparadas com as propriedades dos materiais base - P. Cavaliere e outros [48].

\begin{tabular}{cccc}
\hline Material & $\begin{array}{c}\text { Tensão de } \\
\text { escoamento (MPa) }\end{array}$ & $\begin{array}{c}\text { Tensão de ruptura } \\
(\mathrm{MPa})\end{array}$ & $\begin{array}{c}\text { Alongamento (\%) } \\
\text { AA2024 }\end{array}$ 380 $^{\text {AA7075 }}$ \\
2024-7075 FSW & 503 & 490 & 17 \\
\hline
\end{tabular}

O aspecto das curvas de tensão x deformação segue o aspecto característico dos materiais base, como demonstrado pelas curvas 19 e 20 . 


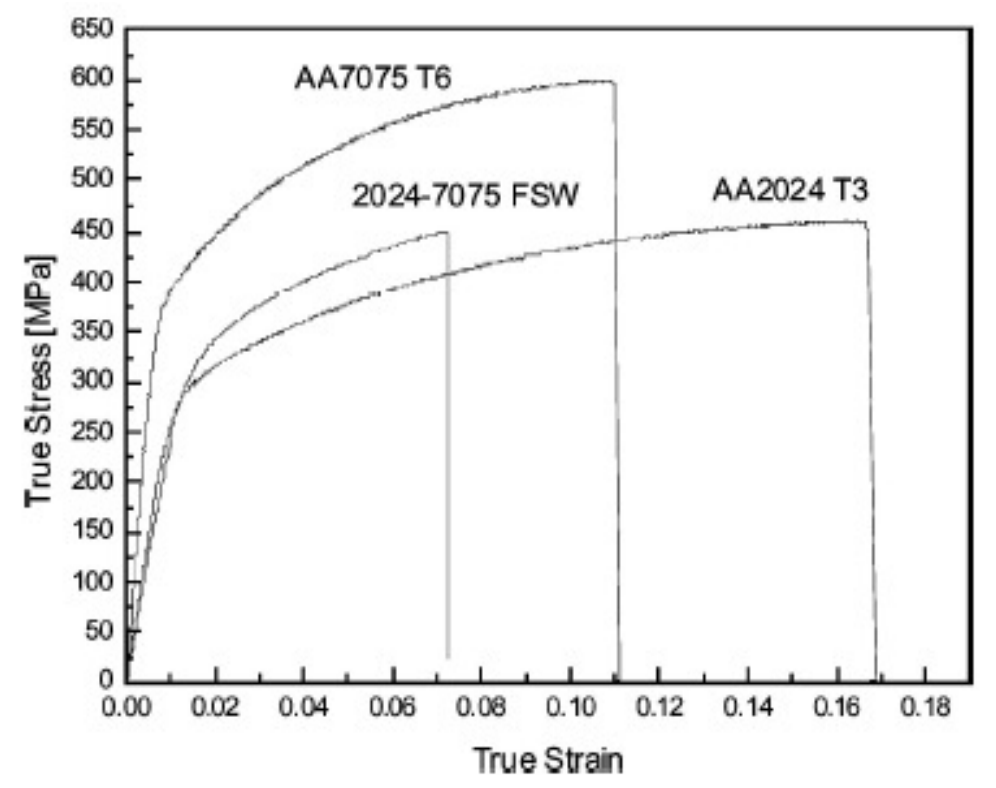

Figura 19 - Curvas de Tensão x Deformação dos materiais AA7075, AA2024 e da união entre AA2024 com AA7075 por FSW - P. Cavaliere e outros [48]

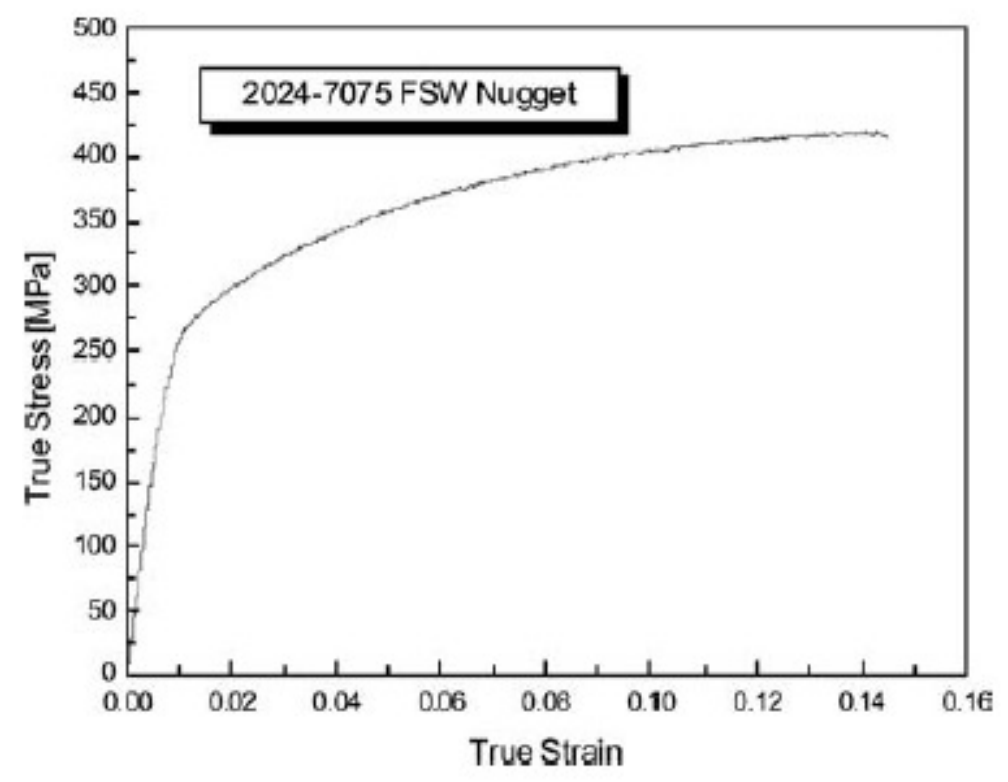

Figura 20 - Curva de Tensão x Deformação da união entre AA2024 com AA7075 por FSW, na região do núcleo - P. Cavaliere e outros [48] 
Os termos escritos em inglês nas figuras 19 e 20 são traduzidos no presente texto como:

"True Stress " : Tensão real

"True Strain " : Deformação real

O comportamento em relação à fadiga mostra que a curva que representa a amplitude de tensão cíclica versus vida em fadiga segue o comportamento clássico das ligas de alumínio, onde existe a tendência de aumento da vida em fadiga com a redução da amplitude da tensão cíclica, conforme apresentado na figura 21.

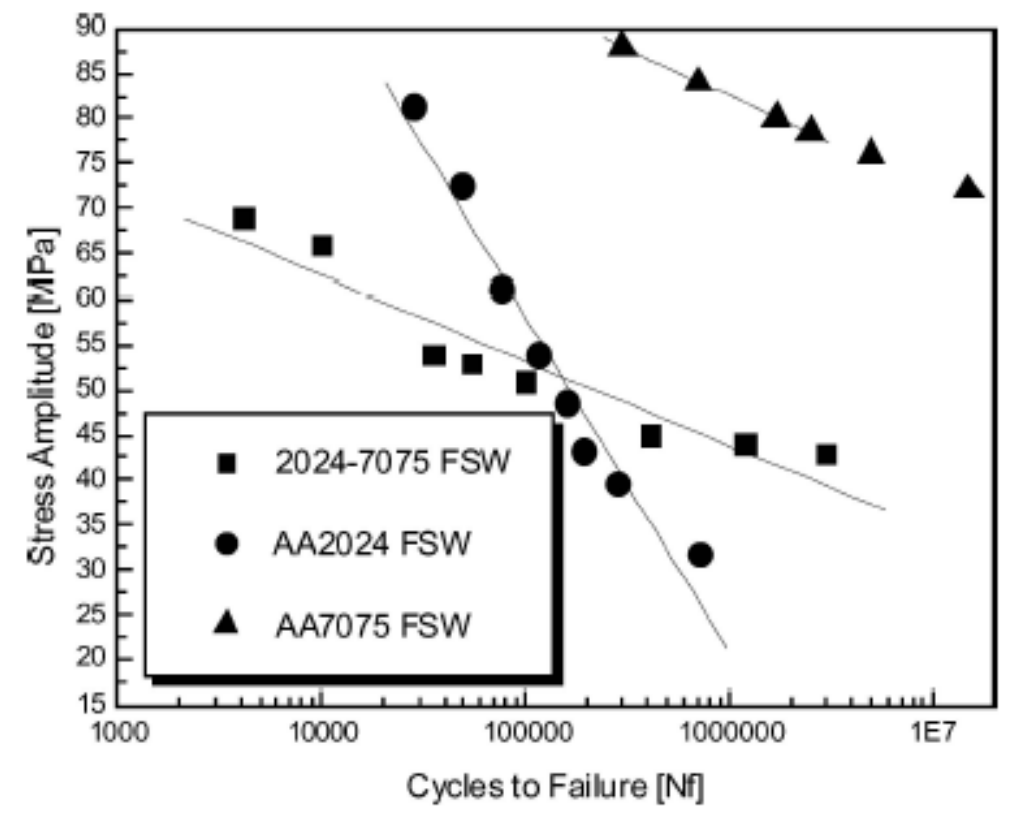

Figura 21 - Curva de fadiga dos materiais AA2024, AA7075 e da união entre os materiais AA2024 e AA7075, relacionando número de ciclos e amplitude de esforços - P. Cavaliere e outros [48]

Os termos escritos em inglês na figura 21 são traduzidos no presente texto como:

"Strength " : Resistência ( mecânica)

"Elongation " : Alongamento 
"Hardness " : Dureza

"Distance " : Distância

\section{6 - Comparativo entre comportamento mecânico de painéis soldados por FSW e painéis rebitados.}

Conforme estudo apresentado por Widener na Universidade de Wichita - EUA [11], as características mecânicas resultantes para painéis aeronáuticos soldados por FSW são superiores às características encontradas em painéis rebitados. $O$ estudo levou em consideração painéis compostos por chapas de material AA 2024 e longarinas de material AA 7075.

Os resultados encontram-se listados abaixo, e referem aos painéis unidos por FSW em relação aos painéis unidos por rebites.

\section{- Tensão}

- Dez por cento de aumento em tensão limite de ruptura.

- Quarenta e um por cento de aumento no alongamento total.

- Compressão

- Equivalente aos esforços suportados pelo painel rebitado

- Painéis formados por FSW continuam a torcer após falha, enquanto painéis rebitados falham catastroficamente.

- Cisalhamento

- Oito por cento de aumento na tensão limite de ruptura comparado a painéis rebitados

- Os painéis unidos por FSW se mostraram capazes de dissipar energia de deformação de forma menos abrupta que os painéis unidos por rebites, mantendo suporte à carga enquanto sujeito a dano nas longarinas. 
Na figura 22, pode-se ver imagem do painel de teste utilizado no estudo comparativo acima descrito.

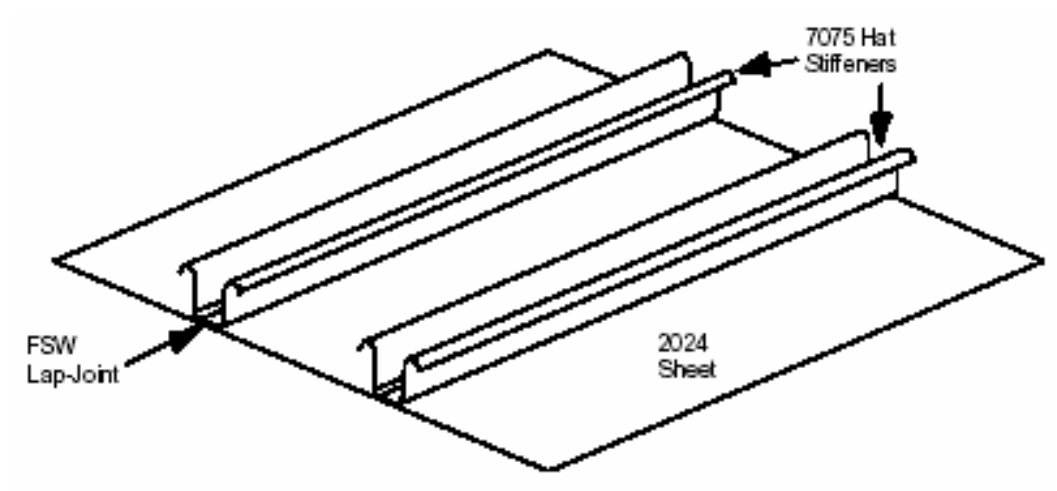

Figura 22 - llustração do painel padrão utilizado para o estudo desenvolvido por Widener C. [11].

Os termos escritos em inglês na figura 22 são traduzidos no presente texto como:

“ 7075 Hat Stiffeners “ : Elementos de enrijecimento - Material AA 7075

" Lap-Joint " : Junção sobreposta

“ 2024 Sheet “ : Chapa - Material AA 2024

Os resultados dos ensaios são mostrados nos gráficos das figuras 23 e 24 : 
Stiffened Panel Tension Test

FSW vs. Riveted

7075-T6 to 2024-T3

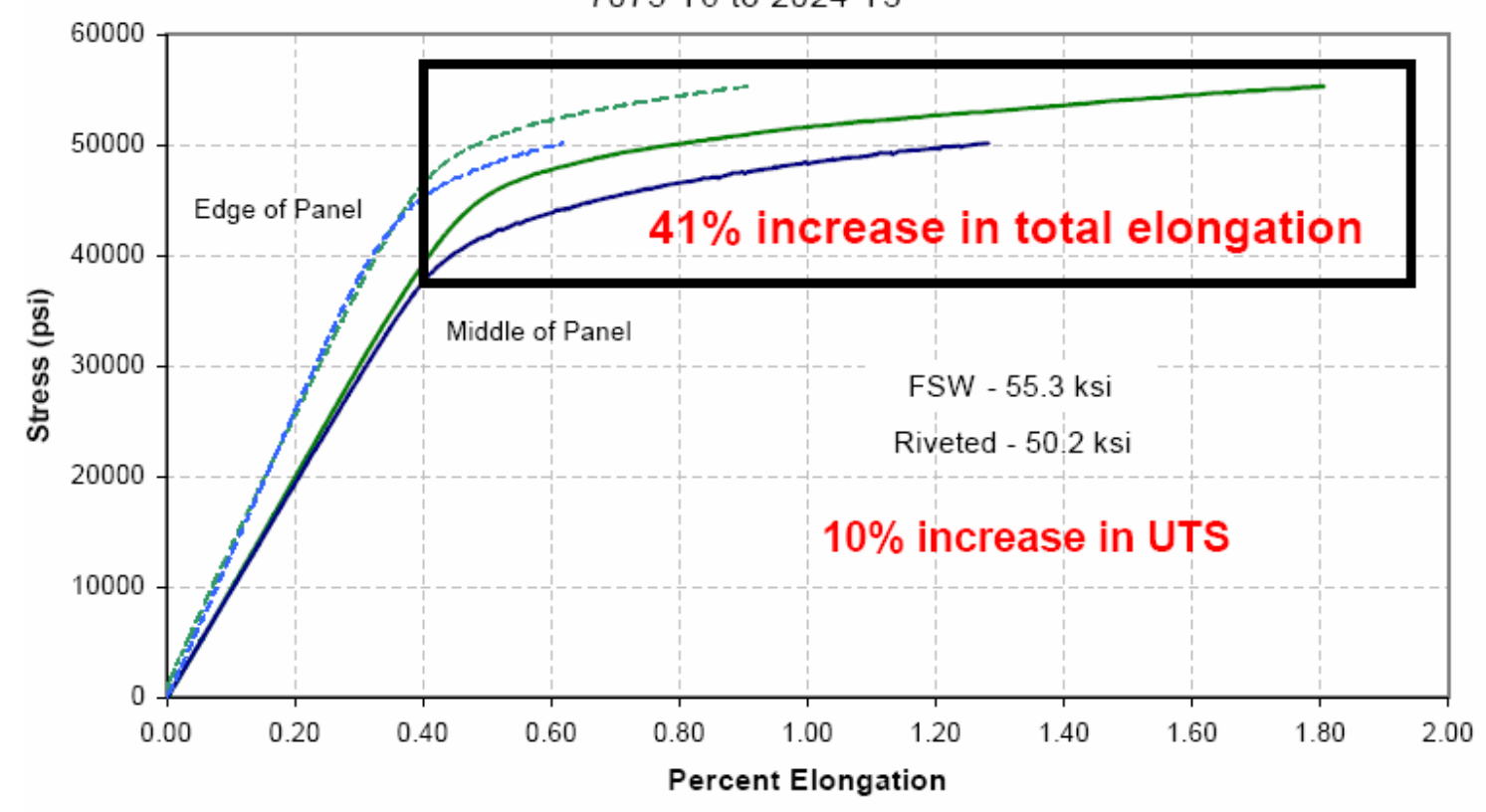

Figura 23 - Ensaio de tensão para painéis enrijecidos - Materiais AA7075-T6 e AA2024-T3, unidos pelos processos FSW e Rebitagem - Widener C. [11].

\section{Comparison of Shear Testing Results for FSW and Riveted Panels}

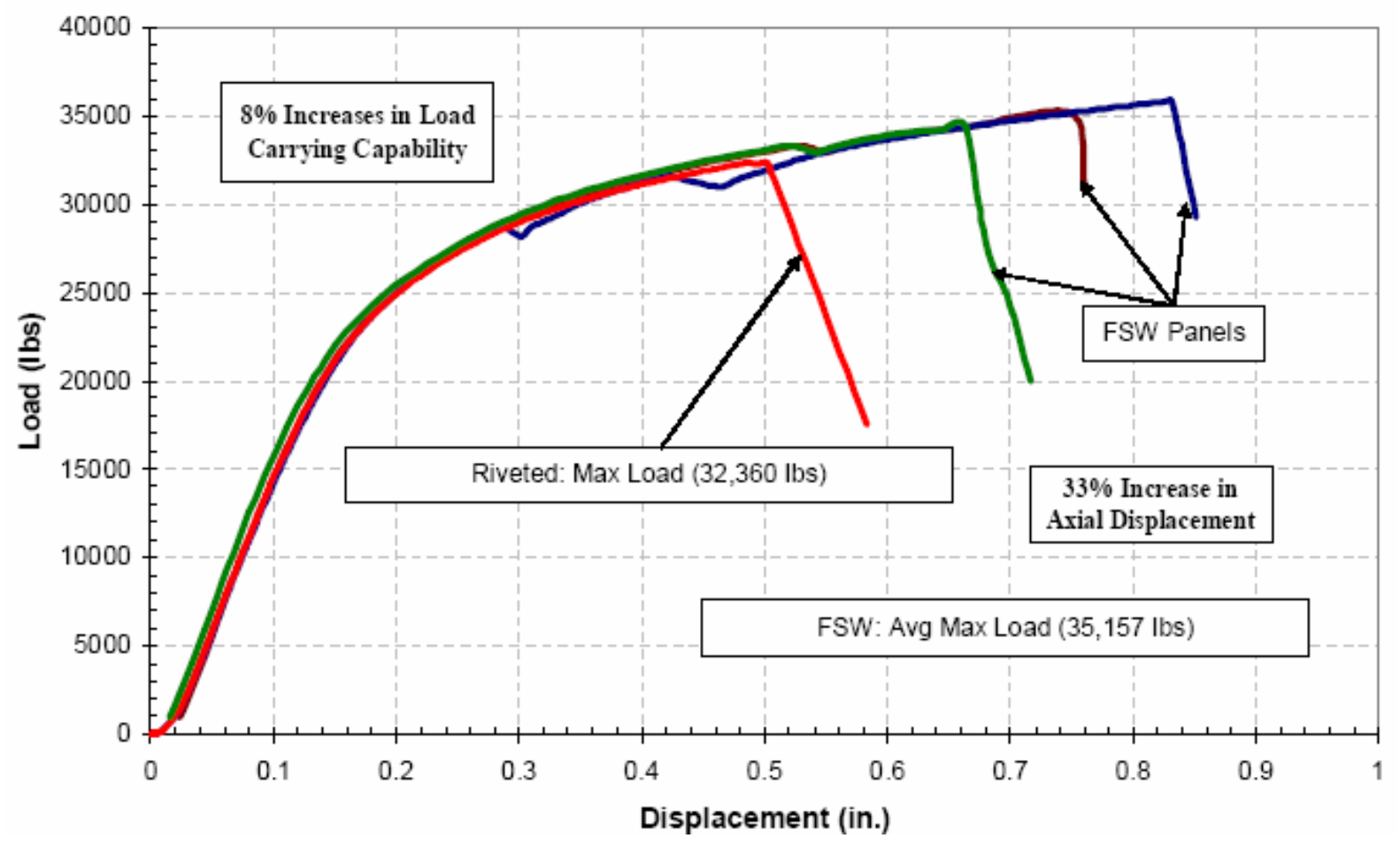

Figura 24 - Comparação entre ensaios de cisalhamento para painéis rebitados e unidos por FSW - Widener C. [11]. 
Os termos escritos em inglês na figura 23 e 24 são traduzidos no presente texto como:

"Stress " : Tensão

"Percent Elongation " : Alongamento Percentual

"Edge of panel " : Borda do painel

"Middle of panel " : Centro do painel

"Increase in total elongation " : Aumento no alongamento total

"Increased in UTS " : Aumento na tensão máxima de ruptura

"Riveted ": Rebitado

"Avg. Max Load " : Carga máxima média

"Max Load " : Carga Máxima

"Load " : Carga

" Displacement " : Deslocamento

"Increases in load carrying capability " : Incremento na capacidade de carga

"Increase in axial displacement " : Incremento no deslocamento axial

"Panels ": Painéis

Os painéis formados por FSW foram capazes de dissipar a energia de deformação de forma menos abrupta e foram capazes de continuar a suportar carga apesar de danos nas longarinas, conforme documentado na figura 25.

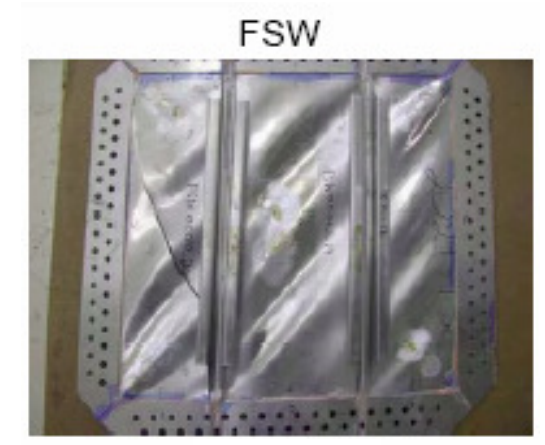

Rebitado

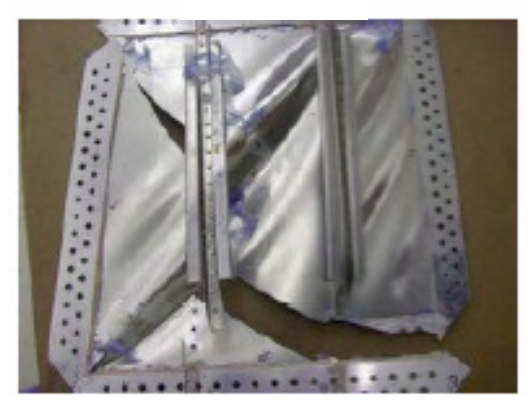

Figura 25 - Falha em painéis unidos por FSW e por rebites, sujeitos aos mesmos esforços - Widener C. [11]. 
Conforme apresentado neste capítulo, pode-se perceber que a resistência mecânica obtida com a junção de componentes das ligas AA 2024 e AA 7075, desde que manufaturados com processos adequados será superior à resistência mecânica obtida por painéis manufaturados por rebitagem, e o modo de falha apresentado pelos painéis unidos por FSW é mais brando que o apresentado pelos painéis rebitados.

A resistência à fadiga apresentada pelos painéis unidos por FSW tem características superiores aos painéis unidos por rebitagem.

Sob o ponto de vista de comportamento mecânico, é previsto que a união das longarinas e chapas por FSW mantenha, no mínimo as características existentes nas estruturas rebitadas, sendo esperado que algumas sejam melhoradas. 


\section{5 - Comparação entre painéis manufaturados com longarinas rebitadas e com longarinas soldadas por FSW .}

Neste capítulo, são apresentadas diferenças de processo produtivo entre os métodos de construção de estruturas aeronáuticas por rebitagem e por FSW.

A indústria de construção aeronáutica historicamente utiliza na construção de fuselagens, painéis de alumínio reforçados por longarinas e cavernas, também de alumínio, unidos mecanicamente por rebites. Algumas das razões para a escolha desta forma de união, no passado, foram :

- Uso de ferramentas simples

- Baixo investimento inicial

- Disponibilidade no mercado

- Compatibilidade dos materiais com a estrutura da aeronave

Também são fatores determinantes sua resistência à corrosão e a dificuldade de soldar os componentes da estrutura da aeronave pelos processos tradicionais.

O processo de aplicação de rebites sólidos, utilizados na junção dos componentes longarina e chapa de fuselagem, existe a necessidade de dois técnicos posicionados um em cada lado da estrutura a ser unida, e a velocidade média do processo é de cerca de 30 rebites por hora. [49]

Conforme citado por Abel Rosato Junior, em sua tese de mestrado [49], o processo de solda por FSW é capaz de efetuar junções até sessenta vezes mais rápidas que as produzidas pelo processo manual de rebitagem. A origem destas informações é o documento "Fatigue of Metals " de S. Surish, editado pela universidade de Cambridge em 1998, citado pelo autor da tese.

Ainda conforme este autor, a empresa Eclipse Aviation, fabricante norte americana de jatos executivos de pequeno porte e baixo custo, informa incremento na produtividade da operação de junção de painéis, onde a velocidade aumentou de $50,8 \mathrm{~mm} / \mathrm{min}$ para $1016 \mathrm{~mm} / \mathrm{min}$ ao passar do processo de rebitagem para o de união através de FSW. As informações teriam sido retiradas da publicação “ New Jet 
Will Stir Up Aircraft Assembly", de J. Ogando, Design New Magazine, EUA, 2001.

Para confecção do painel padrão de dimensões conforme desenho 1 são necessários:

Processo de rebitagem:

- 130 rebites por longarina (passo de $20 \mathrm{~mm}$ ).

- 1820 rebites por painel para fixar todas as longarinas.

\section{Processo FSW}

- Comprimento da solda por longarina: 2,6 m.

- Comprimento de solda para fixar todas as longarinas no painel: 36,4 m.

\section{1 - Produtividade}

Para fixação de 14 longarinas no painel padrão adotado neste estudo, são necessários 1820 rebites, ou $36,4 \mathrm{~m}$ de solda. De acordo com os índices de produtividade apresentados no item 4, seriam necessárias as horas produtivas abaixo apresentadas:

- Rebitadeira Manual: T=(1820/30)x2 =121,32 hs ( 2 técnicos )

- FSW ( velocidade de $1016 \mathrm{~mm} / \mathrm{min}$ ): $\mathrm{T}=36400 / 1016=35,82 \mathrm{~min}=0,60 \mathrm{hs}$

No presente estudo são adotadas as premissas :

- Custo de mão de obra para rebitagem : $\quad R \$ 25,00 / h$

- Custo de mão de obra para FSW : $\quad R \$ 40,00 / h$

- Custo de aquisição - equipamento para rebitagem : $R \$ 3000,00$ ( Apêndice 1 )

- Custo de aquisição de equipamento FSW : R\$ 700.000,00 (Apêndice 2 ) 
- Os custos de importação e instalação do equipamento FSW são considerados equivalentes a $40 \%$ do custo do equipamento, resultando em $R \$ 280.000,00$.

- O custo do desgaste da ferramenta de usinagem FSW é considerado equivalente ao custo de aquisição dos rebites necessários para montar o painel.

- O processo de rebitagem necessita de gabarito para fixação das partes à serem unidas, e o processo de união por FSW necessita fixação em sistema próprio, similar a um gabarito. No presente estudo consideramos que os custos de aquisição e os tempos improdutivos para fixação são equivalentes, e se anulam em um estudo comparativo.

- O sistema de fixação para FSW e o gabarito para rebitagem tem natureza similar e os custos de aquisição de são considerados equivalentes.

- A infra-estrutura necessária para ambos métodos de produção apesar de ser de natureza distinta, é considerada neste estudo como tendo custo de aquisição equivalente.

Os custos de aquisição do equipamento para rebitagem e do equipamento de FSW foram obtidos por cotação de fornecedores.

O custo de mão de obra para produção de um painel por rebitagem é :

$121,32 \mathrm{hs} \times \mathrm{R} \$ 25,00 / \mathrm{h}=\mathrm{R} \$ 3033,00$

O custo de mão de obra para produção de um painel por FSW é :

0,6 hs $\times R \$ 40,00 / h=R \$ 24,00$

O consumo de energia para produção do painel por rebitagem é :

- Consumo de ar na de ferramenta : 7,0 $\mathrm{l} / \mathrm{s}=420 \mathrm{l} / \mathrm{min}$

- $1 \mathrm{Kw}=135 \mathrm{l} / \mathrm{min}$ 
- Consumo de energia na ferramenta : 3,1 Kw

- Tempo de produção de um painel : $1820 \mathrm{~s}(1 \mathrm{~s} /$ rebite $)=30,33 \mathrm{~min}=$ $0,505 \mathrm{~h}$

- Consumo de energia para um painel : 3,1 kw $\times 0,505 \mathrm{~h}=1,57 \mathrm{kw} . \mathrm{h}$

O consumo de energia para produção do painel por FSW é :

- Consumo de energia do equipamento : 7,5 Kw

- Tempo de produção de um painel :0,6 h

- Consumo de energia para um painel : 7,5 Kw x 0,6 h=4,5 Kw.h

Considerando-se o custo da energia elétrica como $\mathrm{R} \$ 0,28 / \mathrm{Kw} . \mathrm{h}$, obtemos os custos de energia :

- Painel rebitado : $\mathrm{R} \$ 0,28 \times 1,57 \mathrm{Kw} \cdot \mathrm{h}=\mathrm{R} \$ 0,44$

- Painel soldado por FSW : $\mathrm{R} \$ 0,28 \times 4,5 \mathrm{Kw} \cdot \mathrm{h}=\mathrm{R} \$ 1,26$

A diferença de custo para produção de um painel por rebitagem e por FSW é :

$(R \$ 3033,00+R \$ 0,44)-(R \$ 24,00+R \$ 1,26)=R \$ 3008,18 /$ painel

O número de painéis estimados para retorno do investimento no equipamento FSW é :

$[(R \$ 700.000,00+R \$ 280.000,00)-R \$ 3000,00] / R \$ 3008,18=324,78$ paineis

Nas condições apresentadas para a produção de um painel padrão conforme descrito no desenho 1, o investimento para produção pelo processo FSW seria recuperado após a produção de trezentos e vinte e cinco paineis, quando comparado com a produção pelo processo de rebitagem. 
A avaliação de custos apresentada neste capítulo é aproximada e dependente de uma série de premissas. Cada empresa que tenha intenção de inserir em seu processo produtivo a tecnologia de FSW terá uma estrutura de custos própria e dependente de fatores internos, não levados em consideração neste trabalho, portanto, esta avaliação tem um caráter de indicador de tendências, apresentando valores aproximados para um caso específico. Recomenda-se que todas as empresas que estejam avaliando a possibilidade de introduzir o processo FSW façam sua própria avaliação econômica para obter maior precisão nos valores.

Esta avaliação mostra a possibilidade de um significativo ganho em redução de mão de obra e um expressivo aumento na velocidade de produção, indicando que o processo FSW tem grande potencial para substituir o processo de união por rebitagem, sob o ponto de vista econômico. 


\section{6 - Efeitos da construção de aeronaves com painéis formados por FSW na manutenção e operação}

A manutenção de aeronaves segue padrões estabelecidos através da experiência adquirida em aproximadamente cem anos de existência desta indústria.

As tarefas constantes em um plano de manutenção aeronáutica conferem característica preventiva à conservação da aeronave, implementando inspeções periódicas em sistemas e na estrutura da mesma.

As inspeções relacionadas à estrutura da aeronave buscam por trincas e componentes com indícios de corrosão. Elas podem ser visuais ou se utilizar de métodos variados como o uso de líquido penetrante, correntes parasitas ( também conhecido como método Eddy Current ), ultrassom e radiografia.

O uso do processo FSW para união de componentes estruturais não altera os métodos usuais de inspeção para busca de trincas ou de corrosão.

Como forma de redução dos custos de manutenção da aeronave, as trincas usualmente têm parâmetros de tolerância admissíveis para forma e dimensões. Os parâmetros são obtidos através de técnicas de previsão da propagação das trincas, e ensaiados para validação em modelos de dimensões reais, sujeitos a esforços equivalentes aos esforços atuantes na operação da aeronave, porém em ritmo acelerado. $O$ estudo resultante determina as condições permissíveis de falha que ainda garantem a operação segura da aeronave. Processos como este devem ser ratificados pela autoridade aeronáutica, no caso brasileiro a ANAC - Agência Nacional de Aviação Civil, para homologação da aeronave.

As técnicas atuais de previsão da propagação são baseadas em estruturas rebitadas sendo esperado que necessitem de ajustes para se adequar à condição de elementos fixados através de solda. Desta forma, ao passar para o uso da nova tecnologia de fixação por FSW, deverá ser necessário um trabalho de engenharia para determinação de novos parâmetros de controle para trincas. Seria necessário certificar novamente o envelope de utilização, o plano de manutenção e a árvore de falhas da aeronave. Os custos de engenharia e os prazos envolvidos sugerem que 
seja mais adequado implantar a tecnologia de fixação por FSW em novos programas de desenvolvimento de aeronaves do que em programas já existentes, porém não é esperado que existam impactos significativos nos custos operação de uma aeronave que possui as longarinas fixadas por FSW, quando comparada com outra que possui as longarinas rebitadas. 


\section{7 - Conclusões e trabalhos futuros}

De acordo com os números $\mathrm{e}$ as condições apresentadas na avaliação de viabilidade econômica, o investimento para a introdução do processo FSW na produção de paineis de construção aeronautica se justifica principalmente pela redução substancial de mão de obra produtiva necessária e do aumento de produtividade obtido.

Sob o ponto de vista do comportamento mecânico das uniões executadas pelo processo FSW, em comparação com as uniões executadas por rebitagem, é possível afirmar que a nova tecnologia FSW pode ser introduzida nos projetos aeronáuticos sem que se façam necessárias alterações significativas nos métodos de cálculo para dimensionamento de estruturas.

É esperado que existam alterações no plano de manutenção da aeronave, porém não se espera impacto significativo.

Como os aspectos relativos à possibilidade de manufatura, comportamento mecânico e resistência à fadiga e os aspectos econômicos relacionados não mostram impedimentos à substituição do processo de rebitagem pelo processo FSW para união de longarinas às chapas na confecção de painéis aeronáuticos, mas pelo contrário, indicam potenciais ganhos, entende-se que esta tecnologia apresenta possibilidades reais de melhoria dos processos produtivos na indústria aeronáutica.

Futuros trabalhos sobre este tema poderiam investigar a utilização de sistemas robóticos de produção aplicados à produção de painés aeronáuticos. Os componentes a serem fixados poderiam não ser limitados à fixação das longarinas e chapas de fuselagem, objeto deste estudo, mas incluir a fixação das cavernas, automatizando por completo o processo produtivo. 


\section{Referencias Bibliográficas}

[1]- Wittman R. J., Pires P. C., Brandi S. D.; Friction Stir Welding - Overview and Perspectives

[2]- Defalco J.; Friction Stir Welding vs. Fusion Welding - Welding Journal $85, \mathrm{n}^{\circ} 3$ - Março 2006

[3]- Mendez P. F., Eagar T. W.; Welding Process for Aeronautics - Advanced Materials and Process - Maio 2001

[4]- Irving B.; Why Aren't Airplanes Welded? - Welding Journal - Janeiro 1997

[5]- Norman A.F., Brough I., Prangnell P.B.; High Resolution EBSD Analysis of the Grain Structure in an AA 2024 Friction Stir Weld - Aluminum Alloys - Their Physical and Mechanical Properties - Ano 2000 pp: 1713 - 1718 - Materials Science Forum - Vols 331-337

[6]- Aircraft Sheet Metal - Aviation Technician Training Series - USA - Texto de material didático utilizado no treinamento de mecânicos de aviação especializados em rebitagem de estruturas.

[7]- Muller R.P.G.; An experimental and Analytical Investigation on the Fatigue Behavior of Fuselage Riveted Lap Joints - Tese de Doutorado - Universidade de Delft, Holanda, 1995

[8]- Schutz W.; Endurance of Single Shear Light Alloy Riveted Joints - LBF, Berich no F-47, 1963

[9]- Stephan W. K., Nicholas E. D., Thomas W. M.; Friction Stir Welding Invention, Innovations ans Applications $-8^{\text {th }}$ International Conference on Joints in Aluminium - Munich - Germany - 2001

[10]- Santiago D. H., Lombera G., Urquiza S., Cassanelli A., Vedia L.A.; Numerical Modeling of Welded Joints by the "Friction Stir Welding "Process Universidade de Mar del Plata e Universidade Nacional de San Martin - Argentina 2004

[11]- Widener C.; Evaluation of Friction Stir Welding Process and Properties for Aircraft Application - Wichita State University - EUA - 2006. Trabalho apresentado em evento do FAA ( autoridade aeronáutica norte americana ) de nome JAMS ( Joint Advanced Materials and Structures Center of Execellence ) ocorrido entre 20 e 22 de junho de 2006 na Universidade de Washington, em Seattle, EUA. Cópia da apresentação foi obtida $\quad$ no $\quad$ site (http://depts.washington.edu/amtas/events/jams 06/presentations.html)

[12]- Reynolds A.P., Tang W. Gnaupel-Herold T. Prask H.; Structure, Properties and Residual Stress of 304L Stainless Steel Friction Stir Welds - 2003

[13]- Luan G., Wang Y., Yajuan J.I., Sun C.; Friction Stir Welding of Aluminum Cast Alloy $-5^{\text {th }}$ International Friction Stir Welding Symposium - Metz - France, 2004 
[14]- Wang D., Shuhua L., Zhaoxia C.; Study of Friction Stir Welding of Aluminum - Journal of Materials Science 39 ( 2004 ) 1689 - 1693

[15]- Attallah M., Salem H.G.; Effect of Friction Stir Welding Process Parameters on the Mechanical Properties of the As-Welded and Post-Weld Heat Treated AA 2095 - University of Birmingham - American University in Cairo

[16]- Lee Won-Bae, Jung Seung-Boo; The Joint Properties of Cooper by Friction Stir Welding - Materials Letters 58 ( 2004 ) 1041-1046

[17]- Cederqvist L., Reynolds A.P.; Factors Affecting the Properties of Friction Stir Welded Aluminum Lap Joints - Welding Journal 80 nำ12 D 2001

[18]- Fonda R.W., Bingert J.F., Colligan K.J.; Development of Grain Structure During Friction Stir Welding - Scripta Materialia 51 ( 2004 ) 243-248

[19]- Cederqvist L.; FSW to Seal 50 mm Thick Cooper Canisters - A Weld That Lasts for 100.000 Years - Swedish Nuclear Fuel and Waste Management Co.

[20]- Midling O.T.; High Speed Friction Stir Welding of Aluminium Panels for Transport Applications - Materials Science Forum Vols 426 - 432 ( 2003 ) pp. 2897 $-2902$

[21]- Khaled T.; An Outsider Looks at Friction Stir Welding - Federal Aviation Administration - Report ANM-112N-05-06 - FAA - USA - Julho 2005

http://www.faa.gov/aircraft/air_cert/design_approvals/csta/publications/media/friction_ stir_welding.pdf

[22]- Chen Y.K., Han L., Chrysanthou A., O'Sullivan J. M.; Fretting Wear in SelfPiercing Riveted Aluminium Alloy Sheet - Elsevier Science - Wear 255 ( 2003 ) $1463-1470$.

[23]- Webb P., Eastwood S., Fayaweera N., Chen Y.; Automated Aerostructure Assembly - Industrial Robot Journal $32 / 5$ ( 2005 ) 383-387

[24]- Varis J.; Economics of Clinched Joint Compared to Riveted Joint and Example of Applying Calculations to a Volume Product - Journal of Materials Processing Technology - 172 ( 2006 ) 130-138

[25]- Pan T.Y., Joaquin A., Wilkosz D.E., Reatherford L., Nicholson J.M. Feng Z., Santella M L.; Spot Friction Welding for Sheet Aluminium Joining - Ford Motor Company - Oak Ridge National Laboratory, Tenessee, USA

[26]- Colligan K.; Material Flow Behavior During Friction Stir Welding of Aluminium - Welding Journal - Julho 1999

[27]- Curran R., Price M., Raghunathan S., Bernard E., Crosby S., Castagne S., Mawhinney P.; Integrating Aircraft Cost Modeling nto Conceptual Design Centre of Execellence for Integrated Aircraft Technologies, School of Aeronautical Engineering - Queens University - Belfast - Ireland

[28]- Sato Y.S., Park S.H.C., Michiuchi M., Hiroyuki K.; Constitutional Liquation 
During Dissimilar Friction Stir Welding of Al and Mg Alloys - Scripta Materialia 50 ( 2004 ) 1233-1236

[29]- Yavuz H.; Function Oriented Design of a Friction Stir Welding Robot Journal of Intelligent Manufacturing 15, 761-775, 2004

[30]- Song M., Kovacevic R.; Heat Transfer Modelling for Both Workpiece and Tool in the Friction Stir Welding Process: A Coupled Model - Journal of Engineering Manufacture - Vol 218 Part B, 2004

[31]- Park S.H.C., Sato Y., Kokawa H., Okamoto K., Hirano S., Inagaki M.; Corrosion Resistance of Friction Stir Welded 304 Stainless Steel - Scripta Materialia 51 ( 2004 ) 101-105

[32]- Sharma S.R., Ma Z.Y., Mishra R.S.; Effect of Friction Stir Processing on Fatigue Behavior of A356 Alloy - Scripta Materialia 51 ( 2004 ) 237-241

[33]- Chen C., Kovacevic R.; Thermomechanical Modelling and Force Analysis of Friction Stir Welding by the Finite Element Method - Journal of Mechanical Engineering Science - V 218, Part C, 2004

[34]- Ericsson M., Sandstrom R.; Influence of Welding Speed on the Fatigue of Friction Stir Welds and Comparison with MIG and TIG - International Journal of Fatigue, 2003

[35]- Bussu G., Irving P.E; The Role of Residual Stress and Heat Affected Zone Properties on Fatigue Crack Propagation in Friction Stir Welded 2024-T351 Aluminium Joints - International Journal of Fatigue, 2002

[36]- Colegrove P.A., Shercliff H.R., Hyoe T.; Development of the Trivex (TM )Friction Stir Welding Tool for Making Lap Welds $-5^{\text {th }}$ International Symposium on Friction Stir Welding - Metz, France, 2004

[37]- Chen Z.W., Maginness R.; Formation of Weld Zones During Friction Stir Welding of Aluminium Alloys - Department of Mechanical and Production Engineering, Auckland University of Technology, New Zealand

[38]- Bird C.R.; The Inspection of Friction Stir Welded Aluminium Plant $-5^{\text {th }}$ International Symposium on Friction Stir Welding - Metz, France, 2004

[39]- Davenport A. J., Jariyaboon M., Padovani C., Tareelap N., Connolly B., Williams S., Siggs E.; Corrosion and Protection of Friction Stir Welds - Materials Science Forum Vols 519-521 ( 2006 ) pp. 699-704

[40]- Jata K. V.; Friction Stir Welding of High Strength Aluminum Alloys Materials Science Forum Vols. 331-337 (2000) pp 1701-1712

[41]- Booth, D. and Sinclair, I.; Fatigue of friction stir welded 2024-T351 aluminium alloy. In, Gregson, P.J. and Harris, S. (eds.) Aluminium Alloys 2002. Switzerland, Trans Tech, 1671-1676. (Materials Science Forum 396-402)

http://eprints.soton.ac.uk/22231/ 
[42]- Murphy, A., Price, M., Curran, R.; Integration of Strength and Process Modeling of Friction-Stir-Welded Fuselage Panels - Journal of Aerospace Computing, Information, and Communication Vol.3 Abril 2006

[43]- Chao, Y.J., Wang, Y., Miller, K.W.; Effect of Friction Stir Welding on Dynamic Properties of AA 2024-T3 and AA 7075-T7351 - American Welding Society - Welding Research Supplement - Agosto 2001, pp 196-s a 200-s http://files.aws.org/wj/supplement/Chao08-01.pdf

[44]- Lohwasser, D.; Welding of Airframes by Friction Stir - The Third International Symposium on Friction Stir Welding, Kobe , Japão - Setembro, 2001

[45]- Marie, F.,; Development of Friction Stir Welding of 7000 serie extrusions for central wing box application - The Third International Symposium on Friction Stir Welding, Kobe , Japão - Setembro, 2001

[46]- Burford, D., Widener, C., Tweedy, B.; Advances in Friction Stir Welding for Aerospace Applications $-6^{\text {th }}$ AIAA Aviation Tecnology Integration and Operations Conference - Setembro, 2006 - Wichita - USA

http://www.niar.wichita.edu/media/pdf/nationalpublication/Nov2-06.pdf

[47]- Jata, K.V., Sankaran, K.K., Ruschau, J.J.; Friction-Stir Welding Effects on Microstructure and Fatigue of Aluminum Alloy 7050-T7451 - The Minerals, Metals \& Materials Society - Publicação "Metallurgical and Materials Transactions A, Setembro - 2000 - Volume 31A, pp 2181-2191

[48]- P.Cavaliere, E.Cerri, A.Squillace; Mechanical Response of 2024-7075 Aluminium Alloys Joined by Friction Stir Welding - Journal of Materials Science 40 (2005) 3669-3676

[49]- Abel Rosato Júnior; Estrutura Integral Por Soldagem Por Atrito "Friction Stir Welding “FSW - Requisitos Básicos Para o Projeto Estrutural - Tese de Mestrado - ITA-2003.

[50]- Imagem obtida no endereço: http://www.answers.com/fuselage?cat=technology

[51]- Dados obtidos nos endereços:

AA 2024

http://www.efunda.com/materials/alloys/alloy home/show alloy found.cfm?ID =AA 2024\&prop=all\&Page Title=\%20Metal\%20Alloys\%20Keyword\%20Searc h\%20Results

\section{AA 7075}

http://www.efunda.com/materials/alloys/alloy home/show alloy found.cfm?ID $=$ AA 7075\&prop=all\&Page Title=\%20Metal\%20Alloys\%20Keyword\%20Searc h\%20Results

[52]- Dobrovolski V., Zablonsky K., Radchik e Erlij L. ; Elementos de Máquinas - 3 3 $^{\mathbf{a}}$ edição. 


\section{APÊNDICE 1}

Cotação de ferramenta para produção pelo processo de rebitagem.

Boa Tarde

Sr. Marco

O preço de venda da rebitadeira Emhart - PRG 510A é de $\mathrm{R} \$ 3.000,00$.

Obrigado

Tobias

CASA DE PARAFUSOS SÃO BERNARDO LTDA.

FONE (11) 4339-4755

FAX (11) 4339-4933

casadeparafusos@uol.com.br 


\section{APÊNDICE 2}

Cotação de equipamento para produção pelo processo FSW.

Dear Marco,

Thank you for your inquiry. Please have a look at the LS-C welder on page 4 of the attached brochure. It is available with full features including user-friendly controls and data acquisition system. A system for welding $3000 \mathrm{~mm}$ would be about $\$ 350,000$ US. This is for ROM only.

Good luck with your project.

Tim Haynie

Timothy J. Haynie-PE

President

Transformation Technologies, Inc.

112 Rush Court

Elkhart, IN 46516

Phone: 574-970-4835

Fax: 775-628-3749

web site: www.transformation-tech.com 